\title{
High antibody titres induced by protein subunit vaccines using Mycobacterium ulcerans antigens Hsp18 and MUL_3720 with a TLR-2 agonist fail to protect against Buruli ulcer in mice
}

\author{
Kirstie Mangas $^{1}$, Nicholas Tobias ${ }^{2,3}$, Estelle Marion ${ }^{4,5}$, Jérémie Babonneau ${ }^{4,5}$, Laurent Marsollier ${ }^{4,5}$, Jessica \\ Porter $^{1}$, Sacha Pidot ${ }^{1}$, Chinn Yi Wong ${ }^{1}$, David C Jackson ${ }^{1}$, Brendon Chua ${ }^{\text {Corresp., } 1 \text {, Tim Stinear }}{ }^{\text {Corresp. } 1}$ \\ ${ }^{1}$ Department of Microbiology and Immunology, Peter Doherty Institute for Infection and Immunity, University of Melbourne, Melbourne, Victoria, Australia

Background. Mycobacterium ulcerans is the causative agent of a debilitating skin and soft tissue infection known as Buruli ulcer (BU). There is no vaccine against BU. The purpose of this study was to investigate the vaccine potential of two previously described immunogenic $M$. ulcerans proteins, MUL_3720 and Hsp18, using a mouse tail infection model of BU.

Methods. Recombinant versions of the two proteins were each electrostatically coupled with a previously described lipopeptide adjuvant. Seven C57BL/6 and seven BALB/c mice were vaccinated and boosted with each of the formulations. Vaccinated mice were then challenged with $M$. ulcerans via subcutaneous tail inoculation. Vaccine performance was assessed by time-to-ulceration compared to unvaccinated mice.

Results. The MUL_3720 and Hsp18 vaccines induced high titres of antigen-specific antibodies that were predominately subtype $\operatorname{lgG}_{1}$. However, all mice developed ulcers by day-40 post-M. ulcerans challenge. No significant difference was observed in the time-to-onset of ulceration between the experimental vaccine groups and unvaccinated animals.

Conclusions. These data align with previous vaccine experiments using Hsp18 and MUL_3720 that indicated these proteins may not be appropriate vaccine antigens. This work highlights the need to explore alternative vaccine targets and different approaches to understand the role antibodies might play in controlling BU. 


\section{High antibody titres induced by protein subunit vaccines}

2 using Mycobacterium ulcerans antigens Hsp18 and

3 MUL_3720 with a TLR-2 agonist fail to protect against

4 Buruli ulcer in mice

5

6

7 Kirstie M. Mangas ${ }^{1}$, Nicholas J. Tobias ${ }^{2,3}$, Estelle Marion ${ }^{4}$, Jérémie Babonneau ${ }^{4}$, Laurent

8 Marsollier $^{4}$, Jessica L. Porter ${ }^{1}$, Sacha J. Pidot ${ }^{1}$, Chinn Yi Wong ${ }^{1}$, David C. Jackson ${ }^{1}$, Brendon Y.

9 Chua $^{1, *}$ and Timothy P. Stinear ${ }^{1, *}$.

10

11

${ }^{1}$ Department of Microbiology and Immunology, Peter Doherty Institute for Infection and Immunity, University of Melbourne, Australia

${ }^{2}$ Molekulare Biotechnologie, Fachbereich Biowissenschaften, Goethe-Universität Frankfurt, Frankfurt am Main, Germany

${ }^{3}$ LOEWE Centre for Translational Biodiversity in Genomics (TBG), Germany

${ }^{4}$ CRCINA, INSERM, Université de Nantes, Université d'Angers, Angers, France

Corresponding Authors:

Timothy Stinear, University of Melbourne, 792 Elizabeth St, Melbourne, Victoria, 3000, Australia

Brendon Chua, University of Melbourne, 792 Elizabeth St, Melbourne, Victoria, 3000, Australia Email addresses: tstinear@unimelb.edu.au, bychua@unimelb.edu.au 


\section{Abstract}

26 Background. Mycobacterium ulcerans is the causative agent of a debilitating skin and soft tissue

27 infection known as Buruli ulcer (BU). There is no vaccine against BU. The purpose of this study

28 was to investigate the vaccine potential of two previously described immunogenic M. ulcerans

29 proteins, MUL_3720 and Hsp18, using a mouse tail infection model of BU.

30 Methods. Recombinant versions of the two proteins were each electrostatically coupled with a 31 previously described lipopeptide adjuvant. Seven C57BL/6 and seven BALB/c mice were 32 vaccinated and boosted with each of the formulations. Vaccinated mice were then challenged with 33 M. ulcerans via subcutaneous tail inoculation. Vaccine performance was assessed by time-to34 ulceration compared to unvaccinated mice.

35 Results. The MUL_3720 and Hsp18 vaccines induced high titres of antigen-specific antibodies 36 that were predominately subtype $\operatorname{IgG}_{1}$. However, all mice developed ulcers by day-40 post- $M$. 37 ulcerans challenge. No significant difference was observed in the time-to-onset of ulceration 38 between the experimental vaccine groups and unvaccinated animals.

39 Conclusions. These data align with previous vaccine experiments using Hsp18 and MUL_3720 40 that indicated these proteins may not be appropriate vaccine antigens. This work highlights the 41 need to explore alternative vaccine targets and different approaches to understand the role 42 antibodies might play in controlling BU. 


\section{Introduction}

45 Buruli ulcer (BU) is a disease caused by Mycobacterium ulcerans. M. ulcerans infects

46 subcutaneous tissue and commonly presents as a skin nodule (in Africa) or papule (in Australia),

47 sometimes accompanied by redness; however, oedema is another common initial presentation. As

48 the disease progresses the skin around the infected area breaks down and an ulcer develops [1,2].

49 Ulcers typically present with deep undermined edges and have a necrotic core comprised of slough

50 of bacteria, dead skin and immune cells $[3,4]$. Infections are rarely fatal but untreated ulcers can

51 destroy fat tissue, blood vessels, muscles and bone $[5,6]$.

52

$53 \mathrm{BU}$ endemic areas are focused in certain rural regions across west, sub-Saharan and central Africa,

54 including Nigeria, Ghana, Togo, Cameroon, Benin, Democratic Republic of Congo and Côte

55 d'Ivoire. The disease also occurs in the South-East of Australia [7-10]. The disease can affect all 56 age groups and ethnicities [11].

57

58 M. ulcerans is a slow-growing bacterium, with a doubling time of greater than 48 hours. As such, 59 symptoms of BU can take months to appear after primary infection. If diagnosed early, BU can be 60 treated effectively by combination antibiotic therapy [12]. Unfortunately, in many cases the 61 disease can initially be misdiagnosed as other more common skin infections [13, 14]. Delayed 62 diagnosis and treatment can lead to extensive lesions that leave victims with life-long 63 disfigurement and disability. Reparative surgery is often required for severe cases [15]. A 64 retrospective study in Australia showed that most diagnoses (87\%) occurred once ulceration has 65 been reached [16] and in Ghana 66\% cases were diagnosed with active lesions [17]. There is 66 currently no vaccine for BU and no distinct mechanism of transmission. Furthermore, treatment 
67 can be difficult to access for those in rural areas. Thus, there is a need to develop an effective

68 vaccine to protect those particularly in highly endemic areas.

69

70 The M. bovis 'BCG' vaccine has been shown to delay the onset of BU symptoms and decrease

71 bacterial load in both experimental animal BU infection models and in studies of human 72 populations [18-22]. Therefore, the BCG vaccine is the benchmark for assessing potential $M$.

73 ulcerans vaccines. Some studies have assessed the efficacy of putative BU vaccines although none

74 have reached clinical trials [18, 19, 23-34]. All these vaccines were tested in murine challenge

75 models and were not capable of preventing the eventual onset of disease.

76

77 One approach to vaccination is to use antigens specific for a particular pathogen, e.g. certain 78 proteins(s) that are recognized by the immune system and induce neutralizing antibodies $[35,36]$.

79 Vaccines that utilize only the immune stimulant, such as a protein rather than the whole pathogen, 80 are less likely to induce adverse reactions, therefore could be administered to 81 immunocompromised individuals [35, 37]. For rapid immune recognition these protein antigens 82 would ideally be cell surface associated. Two M. ulcerans proteins MUL_3720 and Hsp18 have 83 been identified as potential candidates for vaccine antigens. Hsp18 is a cell-surface associated 84 protein, with a role in biofilm formation [38]. M. ulcerans-infected individuals produce antibodies 85 against Hsp18 [39, 40]. MUL_3720 is a highly expressed cell-wall associated protein with a 86 putative role in cell-wall biosynthesis [41] and MUL_3720-specific antibodies can be identified in 87 M. ulcerans infected individuals [42].

88

89 Protein antigens generally require an adjuvant to boost immunogenicity and shape immune 90 responses $[43,44]$. A known Toll-like Receptor (TLR)-2 ligand, $\mathrm{R}_{4} \mathrm{Pam}_{2} \mathrm{Cys}$, has been found to 
91 increase antigen uptake, increase dendritic cell trafficking to lymph nodes and enhance antibody

92 production against antigens derived from pathogens including influenza and hepatitis $\mathrm{C}$ in murine

93 models [45-48]. Given BU is a disease where the bacteria can be both extracellular and intracellular

94 [49], the ability of $\mathrm{R}_{4} \mathrm{Pam}_{2} \mathrm{Cys}$ to robustly engage multiple arms of the adaptive immune system

95 may be beneficial for a $\mathrm{BU}$ subunit vaccine. In a recent murine vaccination study, $\mathrm{R}_{4} \mathrm{Pam}_{2} \mathrm{Cys}$ in

96 conjunction with the enoyl reductase domain from the mycolactone biosynthesis machinery,

97 improved protection against Buruli ulcer compared to no vaccine [50].

98

99 The proteins, Hsp18 and MUL_3720 have also been explored in other vaccine studies [26, 27$].$

100 These studies incorporate alternative adjuvants, such as virus replicon particles and EM048, Alum 101 and Sigma adjuvant system in a murine footpad challenge model $[26,27]$. This study focussed on 102 inducing protection through TLR-2 signaling in a murine tail infection model. At the time this 103 study was initiated, no other research using MUL_3720 and Hsp18 in a vaccine had been 104 published. This study was the foundation for the development of the recent low-dose murine tail 105 infection model of BU [50].

107 The aim of this study was to try to develop a preventative vaccine against BU, comprising two 108 highly expressed cell-wall associated proteins, MUL_3720 or Hsp18, bound to an $\mathrm{R}_{4}$ Pam 2 Cys109 based lipopeptide adjuvant evaluated via a murine tail infection model of BU. 
111 Materials \& Methods

112 Strains and culture conditions

113 Escherichia coli Rosetta2 containing plasmid pET30b-Hsp18 (strain TPS681) or pDest17-

114 MUL_3720 (strain TPS682) was grown at $37^{\circ} \mathrm{C}$ in Luria-Bertani (LB) broth (Difco, Becton

115 Dickinson, MD, USA) supplemented with $100 \mu \mathrm{g} / \mathrm{ml}$ ampicillin (Sigma-Aldrich, USA) or 50

$116 \mu \mathrm{g} / \mathrm{ml}$ kanamycin to express 6xHIS-tagged Hsp18 or MUL_3720 recombinant protein.

117 Mycobacterium ulcerans (strain Mu_1G897 from French Guiana [51]) was grown at $30^{\circ} \mathrm{C}$ in $7 \mathrm{H} 9$

118 broth or 7H10 agar (Middlebrook, Becton Dickinson, MD, USA) supplemented with oleic acid,

119 albumin, dextrose and catalase growth supplement (OADC) (Middlebrook, Becton Dickinson,

120 MD, USA), and $0.5 \%$ glycerol (v/v). M. bovis BCG (strain Sanofi Pasteur) used for vaccinations

121 was grown at $37^{\circ} \mathrm{C}$ in $7 \mathrm{H} 9$ broth or $7 \mathrm{H} 10$ agar supplemented with OADC. Mycobacterial colony

122 counts from cultures or tissue specimens were performed using spot plating as previously 123 described [52].

124

125 Recombinant protein expression

126 Overnight cultures of strains TPS681 and TPS682 were diluted to $\mathrm{OD}_{600}=0.05$ in LB broth. Each

127 culture was incubated at $37^{\circ} \mathrm{C}$ with shaking at $200 \mathrm{rpm}$ until $\mathrm{OD}_{600}=0.6-0.7$, then $1 \mathrm{mM} \mathrm{IPTG}$

128 (Isopropyl b-D-1-thiogalactopyr-anoside) was added to induce protein expression. The cells were

129 incubated for a further four hours to express the protein. To harvest the protein, cells were

130 resuspended in wash buffer ( $8 \mathrm{M}$ urea, $150 \mathrm{mM}$ sodium chloride, $10 \%$ glycerol) and sonicated at

131 amplitude 60 (QSonica Ultrasonic Liquid Processor S-4000, Misonix) until the solution turned

132 clear. The lysate was filtered with a $0.22 \mu \mathrm{M}$ filter (Millipore) to remove cellular debris and the

133 protein was column-purified using anti-histidine resin (ClonTech). The resin was washed ten times

134 with 10x column volumes of wash buffer mixed with an increasing proportion of tris buffer (20 
135

136

137

138

139

140

141

142

143

144

145

146

147

148

149

150

151

152

153

154

155

156

157

.

$\mathrm{mM}$ Tris- $\mathrm{HCl}, 150 \mathrm{mM}$ sodium chloride, $10 \%$ glycerol) until the column was washed with only tris buffer. The resin was washed a further two times with tris buffer containing $20 \mathrm{mM}$ imidazole.

Protein was eluted in tris buffer containing $200 \mathrm{mM}$ imidazole and dialysed in phosphate buffered saline (PBS) before concentration using a 3K MWCO PES concentration column (Pierce). Protein was endotoxin purified using Triton X-114 phase separation until less than 0.1 endotoxin unit/ml (detectable limit), measured by PierceTM LAL choromogenic endotoxin quantitation kit (ThermoFisher) as per manufacturer's instructions.

\section{Sodium dodecyl sulphate polyacrylamide gel electrophoresis (SDS-PAGE)}

Samples were denatured in an equal volume of 2 x sample loading buffer $(40 \%(\mathrm{v} / \mathrm{v}) 0.5 \mathrm{M}$ TrisHCL $\mathrm{pH}$ 6.8, 10\% glycerol, 1.7\% (w/v) SDS, 10\% 2- $\beta$-mercaptoethanol, $0.13 \% \quad(\mathrm{w} / \mathrm{v})$ bromophenol blue in distilled water) at $100^{\circ} \mathrm{C}$ for 5 minutes. Ten microlitres of each sample and SeeBlue ${ }^{\circledR}$ Plus2 pre-stained protein standard (Invitrogen) were loaded into a $0.5 \mathrm{~mm} 12 \%$ polyacrylamide gel under reducing conditions, as previously described [53]. The gel was run in running buffer $(0.3 \%(\mathrm{w} / \mathrm{v})$ Tris, $1.44 \%(\mathrm{w} / \mathrm{v})$ glycine and $0.1 \%(\mathrm{w} / \mathrm{v})$ SDS in distilled water $)$ for 1 hour at 150 volts (Mini-protean vertical electrophoresis cell, Bio-Rad). The gels were stained in Coomassie stain (45\% methanol, $10 \%$ acetic acid $0.25 \%(\mathrm{w} / \mathrm{v})$ Coomassie brilliant blue in distilled water) for 1 hour and destained in Coomassie destain (33\% Methanol, 10\% acetic acid, 60\% distilled water) until the protein bands could be identified.

\section{Western Blotting}

Proteins were separated on a $12 \%$ polyacrylamide gel as per the method for SDS-PAGE. After separation proteins were transferred to a nitrocellulose membrane in tris-glycine transfer buffer 
158 (1.5 mM Tris, $12 \mathrm{mM}$ glycine, $15 \%$ methanol (v/v) in distilled water) for 1 hour at 100 volts (Mini

159 Trans-Blot Cell, Bio-Rad). The nitrocellulose membrane was blocked in blocking buffer (5\% (w/v)

160 skim milk powder and $0.1 \%$ Tween-20 in PBS) overnight at $4^{\circ} \mathrm{C}$. The membrane was incubated

161 in blocking buffer containing anti-6xHIS-HRP antibody (Roche Applied Science) at 1:500

162 dilution. The membrane was washed in PBS containing 0.1\% Tween-20 and then exposed to

163 developing solution (Western Lighting Chemiluminescence kit, Perkin Elmer) according to 164 manufacturer's guidelines. Chemiluminescence was detected using an MF ChemiBIS gel imaging 165 system (DNR Bio-Imaging Systems).

166

167

Analysis of electrostatic interaction between protein antigen and lipopeptide formulations

168 The association between each protein and $\mathrm{R}_{4} \mathrm{Pam}_{2} \mathrm{Cys}$ was measured by mixing $25 \mu \mathrm{g}$ of protein 169 with increasing amounts of lipopeptide in $50 \mu 1$ PBS in a 96-well plate (Nunc, Thermo Scientific).

170 The formation of protein-lipopeptide complexes through electrostatic interaction was measured by 171 an increase in light absorbance. Plates were read at dual wavelengths of 505 and $595 \mathrm{~nm}$ on plate 172 reader (LabSystems Multiskan Multisoft microplate reader).

\section{Lipopeptide vaccine preparation}

175 Each vaccine dose contained $25 \mu \mathrm{g}$ protein added to $\mathrm{R}_{4} \mathrm{Pam}_{2} \mathrm{Cys}$ at a ratio of 1:5 mole of protein 176 to lipopeptide. PBS was added to a final volume of $100 \mu 1$ and the combination sonicated in a 177 water bath for 30 seconds. Control vaccine preparations were made containing $25 \mu \mathrm{g}$ protein alone 178 or $\mathrm{R}_{4} \mathrm{Pam}_{2} \mathrm{Cys}$ lipopeptide alone and sonicated before administration.

179

180 Ethics statement for animal experiments 
181 All animal experiments were performed in full compliance with national guidelines (articles R21418287 to R214-90 from French "rural code") and European guidelines (directive 2010/63/EU of the 183 European Parliament and of the council of September 22, 2010 on the protection of animals used 184 for scientific purposes). All protocols were approved by the Ethics Committee of region Pays de 185 la Loire under protocol nos. CEEA 2009.14 and CEEA 2012.145. Animals were maintained under 186 specific pathogen-free conditions in the animal house facility of the Centre Hospitalier 187 Universitaire, Angers, France (agreement A 49007 002). Six-week old female C57BL/6 and $188 \mathrm{BALB} / \mathrm{c}$ mice were obtained from Charles River Laboratories (Saint-Germain-Nuelles, France) 189 and housed at CHU Angers. Food and water were given ad libitum. Animals were euthanized by 190 inhalation of $\mathrm{CO}_{2}$ gas, delivered using a gradual fill method in a chamber containing the animal. 191 All personnel using this technique were appropriately trained to operate the equipment, evaluate 192 animal vital signs and confirm death.

193

194 Vaccination of animals

195 The synthesis and purification of the branched cationic lipopeptide, $\mathrm{R}_{4} \mathrm{Pam}_{2} \mathrm{Cys}$, was performed 196 as previously described $[46,54,55]$. Each vaccine dose contained $25 \mu \mathrm{g}$ protein formulated in PBS 197 with $\mathrm{R}_{4} \mathrm{Pam}_{2} \mathrm{Cys}$ at a 1:5 molar ratio of protein to lipopeptide in a final volume of $100 \mu 1$. The 198 protein alone control formulation contained $25 \mu \mathrm{g}$ protein per dose diluted in $\mathrm{PBS}$. The $\mathrm{R}_{4} \mathrm{Pam}_{2} \mathrm{Cys}$ 199 alone formulations contained the same amount of lipopeptide used in each of the protein + adjuvant 200 formulations, calculated by the 1:5 molecular ratio (with the omission of the protein from the 201 solution). The $\mathrm{R}_{4} \mathrm{Pam}_{2} \mathrm{Cys}$ alone formulations were diluted to the correct concentration in PBS. 202 Live-attenuated $M$. bovis BCG strain 'Sanofi Pasteur' was grown to log phase and stored at $-80^{\circ} \mathrm{C}$ 203 in 20\% glycerol until use. Bacteria were washed with PBS and resuspended in 200ul, before 
204 administration at $4.7 \times 10^{5}$ bacteria per dose. All vaccines and control formulations were sonicated 205 for 5 minutes in a waterbath sonicator before being administered.

206

207

208 For vaccination using $\mathrm{R}_{4} \mathrm{Pam}_{2} \mathrm{Cys}$, animals were inoculated subcutaneously at the base of tail $209(100 \mu 1$ per dose at $50 \mu \mathrm{l}$ per flank) and boosted 21 days later with the same formulations. Mice 210 vaccinated with approximately $1 \times 10^{3} \mathrm{CFU}$ M. bovis BCG resuspended in PBS at the base of tail 211 (100 $\mu 1$ per dose at $50 \mu 1$ per flank).

212

213 M. ulcerans challenge

214 Mice were challenged on day 35 by subcutaneous injection on the tail with $1 \times 10^{4} \mathrm{CFU} M$. 215 ulcerans (Mu_1G897) resuspended in $50 \mu 1$ PBS. Mice were allowed to recover and monitored for 216 up to 40 days after infection and euthanised when tail ulceration was observed wherein sera were 217 obtained for immunological analysis.

218

219 Serum antibody titre measurements

220 Serum was prepared from blood obtained from mice at day 0, day 18, day 33 and day 63. Antibody 221 titres were measured using enzyme linked immunosorbent assay (ELISA) as per methods 222 described in [46]. Briefly, ELISA plates (Nunc, Thermo Scientific) were coated overnight with 5 $223 \mu \mathrm{g} / \mathrm{ml}$ protein diluted in $\mathrm{PBSN}_{3}$ and blocked with $\mathrm{BSA}_{10} \mathrm{PBS}$ for 2 hours at room temperature. 224 Plates were washed with PBS containing 0.05\% Tween-20 (PBST). Neat sera were sequentially 225 diluted in $\mathrm{BSA}_{5} \mathrm{PBST}$ and incubated at room temperature for 6 hours. Bound antibody was detected 226 by adding horse radish peroxidase conjugated rabbit anti-mouse IgG (Dako, Glostrup, Denmark) 
227 or rat anti-mouse IgM, IgG1, IgG2a, IgG2b or IgG3 antibodies (Southern Biotech, USA) at a 228 concentration of 1:400 in $\mathrm{BSA}_{5} \mathrm{PBST}$ for 2 hours. Plates were developed with developing solution 229 (hydrogen peroxide, citric acid and ABTS) and incubated for 10-15 min with gentle agitation to 230 observe a colour change. The reaction was stopped with $50 \mathrm{mM}$ sodium fluoride. Plates were read 231 at dual wavelengths of 505 and $595 \mathrm{~nm}$ on plate reader (LabSystems Multiskan Multisoft 232 microplate reader). The titers of antibody are expressed as the reciprocal of the highest dilution of 233 serum required to achieve an $\mathrm{OD}_{600}$ of 0.2 .

234

235 Statistical analysis

236 Graphpad Prism software (GraphPad Software v7, CA, USA) was used to perform statistical 237 analyses on the antibody titre. Antibody titres were analysed using two-way ANOVA with Tukey’s 238 correction for multiple comparisons. The time-to-ulceration data were displayed as a Kaplan239 Meier plot and statistical significance was determined using a Log-Rank (Mantel-Cox) test. For 240 all tests $* p<0.05, * * p<0.01$ and $* * * p<0.001$ and $* * * * p<0.0001$ were considered statistically 241 significant.

\section{Results}

245 MUL_3720 and Hsp18 have previously been shown to be cell-wall associated and immunogenic 246 in humans [39, 40-42]. The adjuvant $\mathrm{Pam}_{2}$ Cys has been shown to induce strong antibody

247 responses to proteins from infectious agents such as influenza and hepatitis $\mathrm{C}$ in mice [56-58].

248 Therefore, this study measures the ability of MUL_3720 and Hsp18 based vaccines, 249 incorporating the adjuvant Pam2Cys, to generate protein-specific antibodies and to protect 250 against BU. 


\section{Recombinant MUL_3720 and Hsp18 both bound to $R_{4} P_{2} m_{2} C y s$}

253 Recombinant MUL_3720 and Hsp18, expressed from inducible E. coli expression vectors, were 254 prepared for use as antigens in the vaccine formulations (Table S1). Purification of the recombinant 255 proteins was confirmed by SDS-PAGE and Western blot analyses of the eluate (Fig. 1). DLS 256 analysis was then performed to identify whether recombinant MUL_3720 or Hsp18 would 257 electrostatically bind to either the positively charged lipopeptide adjuvant $\mathrm{R}_{4} \mathrm{Pam}_{2} \mathrm{Cys}$, or its 258 negatively charged counterpart, $\mathrm{E}_{8} \mathrm{Pam}_{2} \mathrm{Cys}$. The optical density of solutions containing these 259 constituents at a wavelength of $450 \mathrm{~nm}\left(\mathrm{OD}_{450}\right)$ is related to the particle size of molecules in 260 solution, reflecting the strength of the ionic interaction between protein and lipopeptide [46]. 261 MUL_3720 preferentially bound to $\mathrm{R}_{4} \mathrm{Pam}_{2}$ Cys compared to $\mathrm{E}_{8} \mathrm{Pam}_{2}$ Cys (Fig. 2A, Table S2). This 262 is shown as a gradual increase in optical density following the addition of increasing amounts of $263 \mathrm{R}_{4} \mathrm{Pam}_{2}$ Cys to a constant amount of MUL_3720. At a 5-fold molar excess of protein to lipopeptide 264 the $\mathrm{OD}_{450}$ plateaued, suggesting MUL_3720 bound most strongly to $\mathrm{R}_{4} \mathrm{Pam}_{2} \mathrm{Cys}$ at a 1:5 protein 265 to lipopeptide ratio. Conversely, when $\mathrm{E}_{8} \mathrm{Pam}_{2} \mathrm{Cys}$ was added to MUL_3720 the optical density 266 remained static and did not increase with increasing lipopeptide concentrations, indicating a lack 267 of binding. Hsp18 also appeared to bind preferentially to $\mathrm{R}_{4} \mathrm{Pam}_{2}$ Cys and also at a 1:5 ratio of 268 Hsp18 to $\mathrm{R}_{4} \mathrm{Pam}_{2}$ Cys (Fig. 2B). Therefore, two protein-adjuvant formulations were prepared using 269 MUL_3720 with $\mathrm{R}_{4} \mathrm{Pam}_{2}$ Cys and Hsp18 with $\mathrm{R}_{4} \mathrm{Pam}_{2}$ Cys, both at a 1:5 protein to lipopeptide 270 molar ratio.

\section{Vaccination induced strong protein-specific antibody responses}

273 Prior to challenge with M. ulcerans, the ability of the vaccine candidates to generate murine 274 immune responses was assessed. ELISAs were utilized to measure the antibody (IgG) titres in sera 
275 obtained from two strains of mice (BALB/c and C57BL/6) immunized with either MUL_3720 +

$276 \mathrm{R}_{4} \mathrm{Pam}_{2}$ Cys or Hsp18 $+\mathrm{R}_{4} \mathrm{Pam}_{2}$ Cys after the primary vaccination dose (day 18 ) and a secondary 277 dose (day 33) (Fig. 3, Table S3).

278

279 Vaccination with MUL_3720 recombinant protein alone or MUL_3720 $+\mathrm{R}_{4} \mathrm{Pam}_{2}$ Cys were 280 capable of inducing MUL_3720-specific antibody titres in both BALB/c and C57BL/6 strains of 281 mice (Fig. 3A, B). Primary vaccination with MUL_3720 protein alone induced MUL_3720282 specific antibody responses that significantly increased following a vaccine boost $(\mathrm{p}<0.0001$ and $283 p=0.0005$ for BALB/c and C57BL/6, respectively). Additionally, MUL_3720 $+\mathrm{R}_{4} \mathrm{Pam}_{2} \mathrm{Cys}$ 284 generated MUL_3720 specific antibody responses after primary vaccination $(p<0.0001$ in $285 \mathrm{BALB} / \mathrm{c}$ and $\mathrm{C} 57 \mathrm{BL} / 6)$, which were increased after the secondary boost $(p<0.0001$ in BALB/c 286 and $p=0.0035$ in C57BL/6). The titres after the boost in particular were greater than MUL_3720 287 alone vaccination $(p<0.0001$ in $\mathrm{BALB} / \mathrm{c}$ and $p=0.0075$ in $\mathrm{C} 57 \mathrm{BL} / 6)$. Mice that were not 288 vaccinated with recombinant $\mathrm{MUL} \_3720\left(\mathrm{R}_{4} \mathrm{Pam}_{2} \mathrm{Cys}\right.$ alone and $\left.\mathrm{BCG}\right)$ did not have an increase 289 in MUL_3720-specific antibodies compared to naïve mice.

290

291 Vaccination with Hsp18 recombinant protein alone or Hsp18 + $\mathrm{R}_{4} \mathrm{Pam}_{2}$ Cys induced Hsp18292 specific antibody titres in both strains of mice (Fig. 3C, D). Vaccine boost with Hsp18 recombinant 293 protein alone induced significantly higher Hsp18-specific antibody responses in BALB/c mice 294 compared to a single vaccination with Hsp18 protein $(p<0.0001)$. Boosting with protein alone in 295 C57BL/6 did not significantly increase antibody titres. Hsp18 + $\mathrm{R}_{4} \mathrm{Pam}_{2} \mathrm{Cys}$ induced Hsp18296 specific antibody responses in both mouse strains after primary vaccination $(p<0.0001$ in BALB/c 297 and C57BL/6) and the Hsp18-specific antibody titre significantly increased after booster 
298 vaccination $(p<0.0001$ in $\mathrm{BALB} / \mathrm{c}$ and $\mathrm{p}=0.0006$ in $\mathrm{C} 57 \mathrm{BL} / 6)$. In all strains, the antibody titres

299 induced by $\mathrm{Hsp} 18+\mathrm{R}_{4} \mathrm{Pam}_{2}$ Cys were significantly higher than vaccination with $\mathrm{Hsp} 18$ protein 300 alone ( $p<0.0001$ in BALB/c and C57BL/6) (Fig. 3C, D) with negligible levels of antibodies seen 301 in mice vaccinated with only $\mathrm{R}_{4} \mathrm{Pam}_{2} \mathrm{Cys}$, or BCG.

302

Measurement of IgG antibody subtypes following MUL_3720 $+\mathbf{R}_{4} \mathrm{Pam}_{2} \mathrm{Cys}$ and Hsp18 + 304

\section{$\mathbf{R}_{4} \mathbf{P a m}_{2}$ Cys vaccination}

Quantifying levels of IgG antibody shows that the predominant isotypes produced by MUL_3720

were $\operatorname{IgG1}$ and $\operatorname{IgG} 2_{\mathrm{b}}$ (Fig. 3E) with no significant difference between these isotype titres. The antibody titres for both isotypes were highest prior to infection with M. ulcerans (day 33) and decreased after infection by day 63 . This vaccine was capable of inducing IgG2a antibodies, which 309 was detected also on day 33, however in smaller amounts than $\operatorname{IgG}_{1}(p=0.0300$; Fig. 3E).

Similar to vaccination with MUL_3720, Hsp18 was also capable of inducing strong IgG antibody titres. The predominant isotype was IgG1 which $\mathrm{Hsp} 18+\mathrm{R}_{4} \mathrm{Pam}_{2} \mathrm{Cys}$ elicited more than any other isotype including $\operatorname{IgG} 2_{\mathrm{a}}(p=0.0317)$ and $\operatorname{IgG} 2_{\mathrm{b}}$ (although, not significant) (Fig. 3F). Again, these also observed after vaccination with $\operatorname{Hsp} 18$ alone $\left(p<0.0001\right.$ vs $\operatorname{IgG} 2_{\mathrm{a}}$ and $p=0.0001$ vs $\operatorname{IgG} 2_{\mathrm{b}}$, respectively at day 33).

As both vaccines were capable of inducing protein-specific antibody responses, they were tested 
321 delay to the onset of ulceration in a mouse tail infection model. There is a progression of clinical

322 symptoms for Buruli ulcer in this model (Fig. 4). Once ulceration has been reached the disease

323 would likely continue until the tail became necrotic. Therefore, the experimental endpoint was

324 deemed to be the point of ulceration.

325

326 After the scheduled vaccinations, mice were challenged via subcutaneous tail inoculation with $1 \mathrm{x}$

$32710^{4} \mathrm{CFU}$ of M. ulcerans and observed for up to 40 days. In BALB/c and C57BL/6 mice there was

328 no significant difference between the time to ulceration between control mice (mice not vaccinated

329 with recombinant protein, such as $\mathrm{R}_{4} \mathrm{Pam}_{2}$ Cys alone and $\mathrm{BCG}$ ) and mice vaccinated with either

330 MUL_3720 $+\mathrm{R}_{4} \mathrm{Pam}_{2}$ Cys or Hsp18 $+\mathrm{R}_{4} \mathrm{Pam}_{2}$ Cys (Fig. 5A,B). There was also no significant

331 difference in the time to ulceration between mice that were vaccinated with MUL_3720 +

$332 \mathrm{R}_{4} \mathrm{Pam}_{2} \mathrm{Cys}$ or $\mathrm{Hsp} 18+\mathrm{R}_{4} \mathrm{Pam}_{2} \mathrm{Cys}$ and $\mathrm{BCG}$, the benchmark for mycobacterial vaccine efficacy.

333 Signs of infection in mice were visible by day 63 (Table S4 and Table S5) and all mice reached 334 ulceration by day 75, 40 days post-M. ulcerans challenge (Fig. 5A, B).

335

\section{Antibody titres do not correlate with protection against $M$. ulcerans}

337 High antibody titres were observed in all mice vaccinated with either recombinant MUL_3720 or 338 Hsp18, particularly in the secondary response after booster vaccination (Fig. 3A-D) prior to $M$. 339 ulcerans challenge. However, mice vaccinated with protein alone or protein plus lipopeptide 340 adjuvant all succumbed to infection by day 75 . The sera from mice at the day 63 was used to 341 quantify antibody titres during infection. At day 63 all mice still had detectable protein-specific 342 antibodies against the recombinant protein with which they were vaccinated (Fig. 3A-3D). In $343 \mathrm{BALB} / \mathrm{c}$ mice (Fig. 3A,C) the antibody titres at day 63 were lower than after the secondary 
344 response prior to challenge $\left(p<0.0001 \mathrm{Hsp} 18+\mathrm{R}_{4} \mathrm{Pam}_{2} \mathrm{Cys}\right.$ and not significant for MUL_3720 +

$\left.345 \mathrm{R}_{4} \mathrm{Pam}_{2} \mathrm{Cys}\right)$ but remained significantly higher than at day $0(p<0.0001$ for both Hsp18 + $346 \mathrm{R}_{4} \mathrm{Pam}_{2}$ Cys and MUL_3720 $+\mathrm{R}_{4} \mathrm{Pam}_{2}$ Cys). In C57BL/6 mice (Fig. 3B and 3D), antibody titres 347 against MUL_3720 or Hsp18 from mice vaccinated with either protein alone or protein plus 348 lipopeptide adjuvant were also significantly decreased at day 63 compared to the secondary 349 response at day $35\left(p<0.0001\right.$ for MUL_3720 $+\mathrm{R}_{4} \mathrm{Pam}_{2}$ Cys and Hsp18 $+\mathrm{R}_{4}$ Pam $_{2}$ Cys, 350 respectively). Similar to BALB/c mice, the day 63 respective protein-specific antibodies for 351 MUL_3720 $+\mathrm{R}_{4}$ Pam $_{2}$ Cys and Hsp18 $+\mathrm{R}_{4}$ Pam $_{2}$ Cys were significantly higher than at day $0(p<$ 3520.0001 for MUL_3720 $+\mathrm{R}_{4} \mathrm{Pam}_{2}$ Cys and Hsp18 $+\mathrm{R}_{4} \mathrm{Pam}_{2} \mathrm{Cys}$ ).

Challenge with M. ulcerans did not induce protein-specific antibody levels comparable to 355 vaccination with MUL_3720 or Hsp18. MUL_3720 and Hsp18 recombinant proteins are immunogenic and capable of inducing proteinspecific antibody responses after vaccination. However, only minor detectable antibody responses against either recombinant MUL_3720 or Hsp18 at day 63 (Fig. 3A-D) were found in mice vaccinated with $\mathrm{R}_{4} \mathrm{Pam}_{2} \mathrm{Cys}$ alone or BCG then challenged with M. ulcerans. These responses are much lower than the protein-specific antibody responses generated from MUL_3720 or Hsp18 vaccinated mice, particularly in C57/BL6 mice ( $p<0.0001)$ (Fig. 3A-D). Animals from both 362 mouse strains that were vaccinated with $\mathrm{R}_{4} \mathrm{Pam}_{2} \mathrm{Cys}$ alone or BCG showed no increase in proteinspecific antibody responses against either recombinant MUL_3720 and Hsp18 on day 63 post- $M$. ulcerans challenge (Fig. 3A-D), even though these two proteins are both expressed in M. ulcerans.

\section{Discussion}


368 wall associated proteins, Hsp18 and MUL_3720 [38, 39, 41, 42]. Both the MUL_3720 and Hsp18-

369 based vaccines were capable of inducing high antibody titres, but these responses were not

370 associated with protection (Fig. 5). Since our study was conducted, Bolz et al., also reported

371 experimental BU vaccines incorporating Hsp18 and MUL_3720 [26, 27]. These vaccine

372 formulations included the following adjuvants: virus replicon particles [26], TLR-4 agonist

373 EM048, Alum and Sigma adjuvant system [27]. Similar to the findings by Bolz et al, in our study

374 the antibodies produced by MUL_3720 and Hsp18 in conjunction with TLR-2 agonist,

$375 \mathrm{R}_{4} \mathrm{Pam}_{2} \mathrm{Cys}$, were not able to protect against $M$. ulcerans challenge. This may indicate that these

376 proteins, while strongly immunogenic, play no major role in pathogenesis, so targeting them with

377 potentially neutralizing antibodies induced by the vaccine has no impact on disease.

378

379 Alternatively, antibodies raised by these vaccines may not have had the functional potential to 380 control infection. In addition to antigen binding, antibodies engage via their Fc domains with Fc $\gamma$

381 receptors $(\mathrm{Fc} \gamma \mathrm{R})$ present on innate immune cells (NK cells, monocytes, macrophages and 382 neutrophils) to rapidly recruit the anti-microbial activity of the innate immune system. Antibodies 383 with these functions can promote control of a pathogen through the activation of multiple effector 384 cell functions, including Ab dependent cellular cytotoxicity, cellular phagocytosis and/or cytokine 385 and enzyme secretion [59-61]. Recent research has shown that mice lacking antibodies have 386 increased susceptibility to $M$. tuberculosis infection [62] and non-human primates treated to 387 deplete B cells also exhibit increased bacterial burden [63]. Despite the findings of this research, 388 it is likely that B cells and antibody responses still play a role in controlling M. ulcerans infection 389 in this model, albeit with different specificities. A recent study of BU-infected FVN/B mice that 390 are capable of spontaneously healing, has identified significantly higher mycolactone-specific 
391 IgG2a antibodies in the skin compared to non-spontaneously healing mice strains BALB/c and

392 C57BL/6 [64]. As spontaneous healing and spontaneous partial healing of BU are known

393 uncommon occurrences in both humans [65, 66] and mice [67], future research could use human

394 BU patient cohorts and as well as mouse infection models to attempt to characterize the targets,

395 functional and structural aspects of antibody responses that differentiate subjects able to control

396 BU from susceptible subjects. It might then be possible to use B cell probe technologies to isolate

397 Ag-specific memory B cells from individuals that control M. ulcerans infection and then clone the

398 immunoglobulin gene sequences identified [68]. Antigen-specific monoclonal Abs (mAbs) could

399 then be generated and characterized for their in vitro anti-microbial activity and used in in vivo

400 mouse passive transfer studies to determine potential use as mAb therapeutics against BU.

401

402 Another explanation for the ineffectiveness of antibodies in this study may be due to the localized

403 immune suppression induced by the M. ulcerans toxin mycolactone at the site of infection [69].

404 Mycolactone diffuses into tissue surrounding the bacteria [70-72]. Mycolactone is a cytotoxin that

405 modulates the function of several immune cells $[72,73]$. The toxin inhibits the Sec61 translocon,

406 affecting $\mathrm{T}$ cell activation, impairing $\mathrm{T}$ cell responsiveness and distorting cytokine production [71,

407 72]. The mycolactone-induced depletion of $\mathrm{T}$ cell homing to peripheral lymph nodes affects

408 subsequent B-cell activation and migration from the lymphatics [74]. The antibodies induced by

409 the vaccine in this study may be functional but unable to access bacteria within the infection or it

410 may be that multiple effector cell functions have been modulated by mycolactone exposure

411 through interference with receptor expression on key innate immune cells, rendering these cells

412 poorly responsive to antibodies. Suppression of protein-specific antibody production in the

413 presence of mycolactone has been observed [75]. Mycolactone administered to a different location 
414 than the antigen caused no reduction to systemic antigen-specific IgG titres [75], similar to the

415 observations from our study. Monoclonal antibodies against mycolactone have been shown to

416 neutralize the cytotoxic activity of mycolactone in vitro indicating that mycolactone could be a

417 viable vaccine target [76]. A recent study incorporating the enoyl reductase (ER) enzymatic

418 domain, from the polyketide synthases that form mycolactone, has shown a correlation between

419 ER-specific antibodies and protection against the onset of Buruli ulcer [50]. This suggests that 420 there is a role for antibodies in BU protection, though the most effective antigenic targets may be

421 found in the mycolactone biosynthesis pathway.

422

423 The greatest antibody responses were of the IgG1 subclass. Typical antibody responses against 424 proteins occur via B cell isotype switching from IgM (non-specific antibody isotype) to IgG. There 425 are 4 subclasses of $\operatorname{IgG}(\mathrm{IgG} 1, \mathrm{IgG} 2, \mathrm{IgG} 3$ and $\mathrm{IgG} 4)$ and isotype switching to predominantly $\operatorname{IgG} 1$ 426 suggests refinement of immune responses to respond specifically to either MUL_3720 or Hsp18, 427 as IgG1 is capable of binding to protein antigens [77]. IgG1 can also bind all forms of Fc $\gamma \mathrm{R}$ which 428 is required to elicit and mediate effector immune functions as described above [78]. The presence 429 of IgG2 suggest further isotype switching from IgG1 to IgG2 $2_{\mathrm{a} / \mathrm{b}}$ as the immune response develops. 430 IgG2 is less effective at inducing phagocytosis and fixing complement and is more commonly 431 associated with polysaccharide antigens. Though tests on the recombinant proteins had 432 undetectable levels of lipopolysaccharide (LPS), there could be trace amounts from the E. coli 433 expression vector boosting IgG2 responses. This isotype switch may not necessarily be linked to 434 poorer outcomes, as mentioned earlier, spontaneously healing FVN/B mice produce more 435 mycolactone-specific IgG2a than mice that do not spontaneously heal [64]. Studies analysing 436 antibodies generated during leprosy and TB infection show a switch from IgG1 to IgG2 antibodies 
437 for leprosy and a persistence of IgG1 and IgG3 antibodies for TB [79]. As isotype switching of 438 antibodies requires help by T helper cells, future work could therefore also incorporate studies on 439 the effect of vaccination and subsequent $M$. ulcerans-infection on $\mathrm{T}$ cells as well as antibody 440 responses.

441

442 In this study, all mice succumbed to infection in a relatively short period (40 days) compared to 443 previous mouse tail infection models [80] and human $\mathrm{BU}$, where the incubation period is estimated 444 at 4.8 months before the onset of ulceration [81]. All BALB/c and C57BL/6 mice succumbed to 445 infection by 40 days after MU infection, even mice that were vaccinated by M. bovis BCG. $M$. 446 bovis BCG has been previously shown to delay the onset of disease on average by at least 6 weeks $447[18,19,28]$. In this study however, there was no significant difference between mice vaccinated 448 with either MUL_3720 or Hsp18 protein alone or with both proteins plus $\mathrm{R}_{4} \mathrm{Pam}_{2}$ Cys. This 449 suggests that $M$. bovis BCG is ineffective at protecting mice in this model of $M$. ulcerans 450 vaccination. This failure to observe any protective impact of $M$. bovis BCG might be a reflection 451 of the challenge strain of M. ulcerans used (strain Mu_1G897) and/or the high challenge dose used 452 ( $10^{4}$ bacteria). High concentrations $\left(>10^{4}\right.$ bacteria) have not been reported in environmental 453 sources of $M$. ulcerans [82-86], consistent with the hypothesis that a relatively small bacterial 454 inoculum is required to establish $\mathrm{BU}$ [83]. At the time this study was conducted the minimum 455 infectious dose $\left(\mathrm{ID}_{50}\right)$ for $\mathrm{BU}$ had not been determined, however the $\mathrm{ID}_{50}$ has since been identified 456 as approximately $3 \mathrm{CFU}$ [52]. Future studies could use a murine model that is more representative 457 of this low minimum infectious dose, as we recently reported in a subsequent trial of a protein 458 subunit vaccine using the mycolactone PKS domains [50] (discussed below). 
460 As mentioned earlier, two other studies have also used Hsp18 and MUL_3720 proteins in vaccine 461 studies $(29,30)$. Those studies focused on the footpad challenge model whereas this study utilizes 462 a tail infection model. The previously established BU tail challenge model [24], was chosen as it 463 decreases the impact on mouse mobility and may also prevent added trauma, inflammation or 464 secondary infections at the challenge site [87], particularly given that M. ulcerans is a slow 465 growing pathogen and mice can endure symptoms of BU for a number of weeks [24],[80]. This 466 study was a precursor to a recently published study, that utilized a vaccine challenge model that is 467 more representative of a natural M. ulcerans infection, reflected both in the mode of M. ulcerans 468 entry into the subcutaneous tissue and in the dose of bacteria used for challenge [50]. Using a low469 dose challenge model enabled the separation of BCG-protected mice vs unvaccinated mice, a 470 characteristic that we did not observe in the high-dose challenge used in the current study. Thus, a 471 low-dose murine challenge model appears more relevant for measuring BU vaccine efficacy.

472

473 Conclusions

474 Vaccination with either MUL_3720 or Hsp18 proteins induced high antibody titres. These 475 responses were augmented when either protein was linked with the lipopeptide adjuvant $476 \mathrm{R}_{4} \mathrm{Pam}_{2}$ Cys. However, robust antibody responses did not correlate with protection against 477 challenge with M. ulcerans. Future work could test different M. ulcerans antigens in vaccine 478 formulations against Buruli ulcer. As mycolactone is a key virulence factor, neutralising this toxin 479 early in infection by targeting the PKS enzymes required for its biosynthesis could be a focus for 480 future vaccination developments. Using a low M. ulcerans inoculum as a more realistic vaccine 481 challenge dose is also warranted.

482

483 Acknowledgements 
484 We thank Roy Robins-Browne for providing the pET-30b MOD plasmid used for the expression 485 of recombinant Hsp18.

486

487

488

489

490

491

492

493

494

495

496

497

498

499

500

501

502

503

504

505

506

507

508

509

510

511

512

513

514

515

516

517

518

519

520

521

522

523

524

525

526

\section{References}

1. Guarner, J., et al., Histopathologic features of Mycobacterium ulcerans infection. Emerg Infect Dis, 2003. 9(6): p. 651-656.

2. Vincent, Q.B., et al., Clinical epidemiology of laboratory-confirmed Buruli ulcer in Benin: a cohort study. Lancet Glob Health, 2014. 2(7): p. e422-30.

3. Hayman, J. and A. McQueen, The pathology of Mycobacterium ulcerans infection. Pathology, 1985. 17(4): p. 594-600.

4. Oliveira, M.S., et al., Infection with Mycobacterium ulcerans induces persistent inflammatory responses in mice. (0019-9567 (Print)).

5. Woodring, J.H., et al., Update: the radiographic features of pulmonary tuberculosis. Am J Roentgen, 1986. 146(3): p. 497-506.

6. $\quad$ van der Werf, T.S., et al., Mycobacterium ulcerans infection. Lancet, 1999. 354(9183): p. 1013-8.

7. Michael, J.L., et al., Epidemiology of Buruli Ulcer Infections, Victoria, Australia, 20112016. Emerging Infectious Disease journal, 2018. 24(11): p. 1988.

8. Organization, W.H. Buruli ulcer - number of new reported cases. Global Health Observatory data repository 201919 June 2019 [cited 202029 January]; Available from: http://apps.who.int/gho/data/node.main.A1631.

9. Simpson, H., et al., Mapping the global distribution of Buruli ulcer: a systematic review with evidence consensus. Lancet Global Health, 2019. 7(7): p. e912-e922.

10. Bratschi, M.W., et al., Geographic Distribution, Age Pattern and Sites of Lesions in a Cohort of Buruli Ulcer Patients from the Mapé Basin of Cameroon. PLoS Negl Trop Dis, 2013. 7(6): p. e2252.

11. Omansen, T.F., et al., Global Epidemiology of Buruli Ulcer, 2010-2017, and Analysis of 2014 WHO Programmatic Targets. Emerg Infect Dis, 2019. 25(12): p. 2183-2190.

12. Sarfo, F.S., et al., Clinical efficacy of combination of rifampin and streptomycin for treatment of Mycobacterium ulcerans disease. Antimicrob Agents Chemother, 2010. 54(9): p. 3678-85.

13. van der Werf, T.S., et al., Mycobacterium ulcerans disease. Bull World Health Organ, 2005. 83(10): p. 785-91.

14. Guarner, J., Buruli Ulcer: Review of a Neglected Skin Mycobacterial Disease. J Clin Microbiol, 2018. 56(4): p. e01507-17.

15. Herbinger, K.H., et al., Excision of Pre-Ulcerative Forms of Buruli Ulcer Disease: A Curative Treatment? Infection, 2008.

16. Boyd, S.C., et al., Epidemiology, clinical features and diagnosis of Mycobacterium ulcerans in an Australian population. Med J Aust, 2012. 196(5): p. 341-4.

17. Amofah, G., et al., Buruli ulcer in Ghana: results of a national case search. Emerg Infect Dis, 2002. 8(2): p. 167-70.

18. Tanghe, A., et al., Protective Efficacy of a DNA Vaccine Encoding Antigen 85 A from Mycobacterium bovis BCG against Buruli Ulcer. Infect Immun, 2001. 69(9): p. 5403-5411.

Peer] reviewing PDF | (2020:01:45127:1:0:NEW 26 Jun 2020) 
527 19. Tanghe, A., et al., A booster vaccination with Mycobacterium bovis BCG does not increase

528

529

530

531

532

533

534

535

536

537

538

539

540

541

542

543

544

545

546

547

548

549

550

551

552

553

554

555

556

557

558

559

560

561

562

563

564

565

566

567

568

569

570

571 the protective effect of the vaccine against experimental Mycobacterium ulcerans infection in mice. Infect Immun, 2007. 75(5): p. 2642-4.

20. Phillips, R.O., et al., Effectiveness of routine BCG vaccination on buruli ulcer disease: $a$ case-control study in the Democratic Republic of Congo, Ghana and Togo. PLoS Negl Trop Dis, 2015. 9(1): p. e3457.

21. Group, T.U.B., BCG vaccination against mycobacterium ulcerans infection (Buruli ulcer). First results of a trial in Uganda. Lancet, 1969. 293(7586): p. 111-5.

22. Smith, P.G., et al., The protective effect of BCG against Mycobacterium ulcerans disease: a controlled trial in an endemic area of Uganda. Trans R Soc Trop Med Hyg, 1976. 70(56): p. 449-57.

23. Tanghe, A., et al., Improved protective efficacy of a species-specific DNA vaccine encoding mycolyl-transferase Ag85A from Mycobacterium ulcerans by homologous protein boosting. PLoS Negl Trop Dis, 2008. 2(3): p. e199.

24. Coutanceau, E., et al., Immunogenicity of Mycobacterium ulcerans Hsp65 and protective efficacy of a Mycobacterium leprae Hsp65-based DNA vaccine against Buruli ulcer. Microbes Infect, 2006. 8(8): p. 2075-81.

25. Roupie, V., et al., Analysis of the vaccine potential of plasmid DNA encoding nine mycolactone polyketide synthase domains in Mycobacterium ulcerans infected mice. PLoS Negl Trop Dis, 2014. 8(1): p. e2604.

26. Bolz, M., et al., Use of Recombinant Virus Replicon Particles for Vaccination against Mycobacterium ulcerans Disease. PLoS Negl Trop Dis, 2015. 9(8): p. e0004011.

27. Bolz, M., et al., Vaccination with the Surface Proteins MUL_2232 and MUL_3720 of Mycobacterium ulcerans Induces Antibodies but Fails to Provide Protection against Buruli Ulcer. PLoS Negl Trop Dis, 2016. 10(2): p. e0004431.

28. Fraga, A.G., et al., Cellular immunity confers transient protection in experimental Buruli ulcer following BCG or mycolactone-negative Mycobacterium ulcerans vaccination. PLoS One, 2012. 7(3): p. e33406.

29. Watanabe, M., et al., Protective effect of a dewaxed whole-cell vaccine against Mycobacterium ulcerans infection in mice. Vaccine, 2015. 33(19): p. 2232-9.

30. Hart, B.E., L.P. Hale, and S. Lee, Immunogenicity and protection conferred by $a$ recombinant Mycobacterium marinum vaccine against Buruli ulcer. Trials in Vaccinology, 2016. 5: p. 88-91.

31. Converse, P.J., et al., BCG-mediated protection against Mycobacterium ulcerans infection in the mouse. PLoS Negl Trop Dis, 2011. 5(3): p. e985.

32. Hart, B.E., L.P. Hale, and S. Lee, Recombinant BCG Expressing Mycobacterium ulcerans Ag85A Imparts Enhanced Protection against Experimental Buruli ulcer. PLoS Negl Trop Dis, 2015. 9(9): p. e0004046.

33. Hart, B.E. and S. Lee, Overexpression of a Mycobacterium ulcerans Ag85B-EsxH Fusion Protein in Recombinant BCG Improves Experimental Buruli Ulcer Vaccine Efficacy. PLoS Negl Trop Dis, 2016. 10(12): p. e0005229.

34. Trigo, G., et al., Phage therapy is effective against infection by Mycobacterium ulcerans in a murine footpad model. PLoS Negl Trop Dis, 2013. 7(4): p. e2183.

35. Siegrist, C.-A., 2 - Vaccine Immunology, in Plotkin's Vaccines (Seventh Edition), S.A. Plotkin, et al., Editors. 2018, Elsevier. p. 16-34.e7. 
572 36. Plotkin, S.A., Vaccination against the major infectious diseases. Comptes Rendus de

573

574

575

576

577

578

579

580

581

582

583

584

585

586

587

588

589

590

591

592

593

594

595

596

597

598

599

600

601

602

603

604

605

606

607

608

609

610

611

612

613

614

615

l'Académie des Sciences - Series III - Sciences de la Vie, 1999. 322(11): p. 943-951.

37. Clem, A.S., Fundamentals of vaccine immunology. J Global Infect Dis, 2011. 3(1): p. 7378.

38. Pidot, S.J., et al., Regulation of the $18 \mathrm{kDa}$ heat shock protein in Mycobacterium ulcerans: an alpha-crystallin orthologue that promotes biofilm formation. Mol Microbiol, 2010. 78(5): p. 1216-31.

39. Pidot, S.J., et al., Serological evaluation of Mycobacterium ulcerans antigens identified by comparative genomics. PLoS Negl Trop Dis, 2010. 4(11): p. e872.

40. Diaz, D., et al., Use of the immunodominant 18-kiloDalton small heat shock protein as a serological marker for exposure to Mycobacterium ulcerans. Clin Vaccine Immunol, 2006. 13(12): p. 1314-21.

41. Vettiger A, S.N., Ruf M-T, Röltgen K, Pluschke G., Localization of Mycobacterial Antigens by Immunofluorescence Staining of Agarose Embedded Cells. J Mycobact Dis., 2014. 4(3): p. 150.

42. Dreyer, A., et al., Identification of the Mycobacterium ulcerans protein MUL_3720 as a promising target for the development of a diagnostic test for Buruli ulcer. PLoS Negl Trop Dis, 2015. 9(2): p. e0003477-e0003477.

43. Awate, S., L.A. Babiuk, and G. Mutwiri, Mechanisms of action of adjuvants. Front Immunol, 2013. 4: p. 114-114.

44. Coffman, R.L., A. Sher, and R.A. Seder, Vaccine adjuvants: putting innate immunity to work. Immunity, 2010. 33(4): p. 492-503.

45. Chua, B.Y., et al., The use of a TLR2 agonist-based adjuvant for enhancing effector and memory CD8 T-cell responses. Immunol Cell Biol, 2014. 92(4): p. 377-83.

46. Chua, B.Y., et al., Soluble proteins induce strong CD8+ T cell and antibody responses through electrostatic association with simple cationic or anionic lipopeptides that target TLR2. J Immunol, 2011. 187(4): p. 1692-701.

47. Chua, B.Y., et al., Hepatitis C VLPS Delivered to Dendritic Cells by a TLR2 Targeting Lipopeptide Results in Enhanced Antibody and Cell-Mediated Responses. PLOS ONE, 2012. 7(10): p. e47492.

48. Christiansen, D., et al., Antibody Responses to a Quadrivalent Hepatitis C Viral-Like Particle Vaccine Adjuvanted with Toll-Like Receptor 2 Agonists. Vir Immunol, 2018. 31(4): p. 338-343.

49. Torrado, E., et al., Evidence for an intramacrophage growth phase of Mycobacterium ulcerans. Infect Immun, 2007. 75(2): p. 977-87.

50. Mangas, K.M., et al., Vaccine-Specific Immune Responses against Mycobacterium ulcerans Infection in a Low-Dose Murine Challenge Model. Infect Immun, 2020. 88(3).

51. de Gentile, L., et al., Cutaneous ulcer from Mycobacterium ulcerans. Apropos of 1 case in French Guiana. Bulletin de la Société de pathologie exotique (1990), 1992. 85: p. 212-4.

52. Wallace, J.R., et al., Mycobacterium ulcerans low infectious dose and mechanical transmission support insect bites and puncturing injuries in the spread of Buruli ulcer. PLoS Negl Trop Dis, 2017. 11(4): p. e0005553.

53. Laemmli, U.K., Cleavage of structural proteins during the assembly of the head of bacteriophage T4. Nature, 1970. 227(5259): p. 680-5.

Peer] reviewing PDF | (2020:01:45127:1:0:NEW 26 Jun 2020) 
616 54. Sekiya, T., et al., PEGylation of a TLR2-agonist-based vaccine delivery system improves

617

618

619

620

621

622

623

624

625

626

627

628

629

630

631

632

633

634

635

636

637

638

639

640

641

642

643

644

645

646

647

648

649

650

651

652

653

654

655

656

657

658

659

660

661 antigen trafficking and the magnitude of ensuing antibody and CD8(+) T cell responses. Biomaterials, 2017. 137(1878-5905 (Electronic)): p. 61-72.

55. Wijayadikusumah, A.R., et al., Structure-function relationships of protein-lipopeptide complexes and influence on immunogenicity. Amino Acids, 2017. 49(10): p. 1691-1704.

56. Wijayadikusumah, A.R., An evaluation of charged Pam2Cys-based lipopeptides as novel adjuvants for subunit-based vaccines. 2017.

57. Tan, A.C., et al., Intranasal Administration of the TLR2 Agonist Pam2Cys Provides Rapid Protection against Influenza in Mice. Mol Pharm, 2012.

58. Mifsud, E.J., et al., Reducing the impact of influenza-associated secondary pneumococcal infections. Immunol Cell Biol, 2016. 94(1): p. 101-8.

59. Lu, L.L., et al., A Functional Role for Antibodies in Tuberculosis. Cell, 2016. 167(2): p. 433-443 e14.

60. Damelang, T., et al., Role of IgG3 in Infectious Diseases. Trends Immunol, 2019. 40(3): p. 197-211.

61. Chung, A.W., et al., Dissecting Polyclonal Vaccine-Induced Humoral Immunity against HIV Using Systems Serology. Cell, 2015. 163(4): p. 988-98.

62. Maglione, P.J., J. Xu, and J. Chan, B cells moderate inflammatory progression and enhance bacterial containment upon pulmonary challenge with Mycobacterium tuberculosis. J Immunol, 2007. 178(11): p. 7222-34.

63. Phuah, J., et al., Effects of B Cell Depletion on Early Mycobacterium tuberculosis Infection in Cynomolgus Macaques. Infect Immun, 2016. 84(5): p. 1301-1311.

64. Foulon, M., et al., Skin-specific antibodies neutralizing mycolactone toxin during the spontaneous healing of Mycobacterium ulcerans infection. Science Adv, 2020. 6(9): p. eaax7781-eaax7781.

65. Marion, E., et al., Clinical Features of Spontaneous Partial Healing During Mycobacterium ulcerans Infection. Open Forum Infect Dis, 2016. 3(1): p. ofw013.

66. O'Brien, D.P., et al., Spontaneous healing of Mycobacterium ulcerans disease in Australian patients. PLoS Negl Trop Dis, 2019. 13(2): p. e0007178.

67. Marion, E., et al., FVB/N Mice Spontaneously Heal Ulcerative Lesions Induced by Mycobacterium ulcerans and Switch M. ulcerans into a Low Mycolactone Producer. J Immunol, 2016. 196(6): p. 2690-2698.

68. McLean, M.R., et al., Dimeric Fcgamma Receptor Enzyme-Linked Immunosorbent Assay To Study HIV-Specific Antibodies: A New Look into Breadth of Fcgamma Receptor Antibodies Induced by the RV144 Vaccine Trial. J Immunol, 2017. 199(2): p. 816-826.

69. Fraga, A.G., et al., Mycobacterium ulcerans triggers T-cell immunity followed by local and regional but not systemic immunosuppression. Infect Immun, 2011. 79(1): p. 421-30.

70. George, K.M., et al., Mycolactone: a polyketide toxin from Mycobacterium ulcerans required for virulence. Science, 1999. 283(5403): p. 854-7.

71. Boulkroun, S., et al., Mycolactone suppresses $T$ cell responsiveness by altering both early signaling and posttranslational events. J Immunol, 2010. 184(3): p. 1436-44.

72. Baron, L., et al., Mycolactone subverts immunity by selectively blocking the Sec61 translocon. J Exp Med, 2016. 213(13): p. 2885-2896.

73. Ogbechi, J., et al., Inhibition of Sec61-dependent translocation by mycolactone uncouples the integrated stress response from ER stress, driving cytotoxicity via translational activation of ATF4. Cell Death Dis, 2018. 9(3): p. 397.

Peer] reviewing PDF | (2020:01:45127:1:0:NEW 26 Jun 2020) 
662 74. Guenin-Mace, L., et al., Mycolactone impairs T cell homing by suppressing microRNA

663

664

665

666

667

668

669

670

671

672

673

674

675

676

677

678

679

680

681

682

683

684

685

686

687

688

689

690

691

692

693

694

695

696

697

698 control of L-selectin expression. Proc Natl Acad Sci U S A, 2011. 108(31): p. 12833-8.

75. Shinoda, N., H. Nakamura, and M. Watanabe, Suppressive effect of mycolactonecontaining fraction from Mycobacterium ulcerans on antibody production against coadministered antigens. Biomed Res Clin Prac, 2017. 2(1): p. 1-6.

76. Dangy, J.-P., et al., Antibody-Mediated Neutralization of the Exotoxin Mycolactone, the Main Virulence Factor Produced by Mycobacterium ulcerans. PLoS Neglected Tropical Diseases, 2016. 10(6): p. e0004808.

77. Schroeder, H.W., Jr. and L. Cavacini, Structure and function of immunoglobulins. The Journal of allergy and clinical immunology, 2010. 125(2 Suppl 2): p. S41-S52.

78. Sibéril, S., et al., $F c \gamma R$ : The key to optimize therapeutic antibodies? Critical Reviews in Oncology/Hematology, 2007. 62(1): p. 26-33.

79. Sousa, A.O., et al., IgG subclass distribution of antibody responses to protein and polysaccharide mycobacterial antigens in leprosy and tuberculosis patients. Clin Exp Immunol, 1998. 111(1): p. 48-55.

80. Omansen, T.F., et al., In Vivo Imaging of Bioluminescent Mycobacterium ulcerans: A Tool to Refine the Murine Buruli Ulcer Tail Model. Am J Trop Med Hyg, 2019. 101(6): p. 13121321.

81. Loftus, M.J., et al., The incubation period of Buruli ulcer (Mycobacterium ulcerans infection) in Victoria, Australia - Remains similar despite changing geographic distribution of disease. PLoS Negl Trop Dis, 2018. 12(3): p. e0006323.

82. Fyfe, J.A., et al., A major role for mammals in the ecology of Mycobacterium ulcerans. PLoS Neg1 Trop Dis, 2010. 4(8): p. e791.

83. Stinear, T., et al., Identification of Mycobacterium ulcerans in the environment from regions in Southeast Australia in which it is endemic with sequence capture-PCR. Appl Environ Microbiol, 2000. 66(8): p. 3206-13.

84. Williamson, H.R., et al., Detection of Mycobacterium ulcerans in the Environment Predicts Prevalence of Buruli Ulcer in Benin. PLoS Negl Trop Dis, 2012. 6(1): p. e1506.

85. Marion, E., et al., Seasonal and regional dynamics of M. ulcerans transmission in environmental context: deciphering the role of water bugs as hosts and vectors. PLoS Negl Trop Dis, 2010. 4(7): p. e731-e731.

86. Johnson, P.D., et al., Mycobacterium ulcerans in mosquitoes captured during outbreak of Buruli ulcer, southeastern Australia. Emerg Infect Dis, 2007. 13(11): p. 1653-60.

87. Kamala, T., Hock immunization: a humane alternative to mouse footpad injections. J Immunol Methods 2007 328(1-2): p. 204-14 
699 Figure legends

700

701

702

Figure 1. SDS-PAGE and Western Blot Analysis of purified recombinant MUL_3720 and

703

Hsp18 proteins. (A) SDS-PAGE of MUL_3720 protein elution (containing $10 \mu \mathrm{g}$ protein) shows

704

a band $\sim 36 \mathrm{kDa}$. (B) SDS-PAGE of Hsp 18 protein elution (containing $10 \mu \mathrm{g}$ protein) shows a band 705 $\sim 18 \mathrm{kDa}$. (C) Protein in the final MUL_3720 elute was analysed by Western Blot using an anti706 6xHIS-tag antibody to detect the presence of a single band corresponding to the band as the SDS-

707 PAGE analysis. (D) Protein in the final Hsp18 elute was analysed by Western Blot using an anti708 6xHIS-tag antibody to detect the presence of a single band corresponding to the $18 \mathrm{kDa}$ band as 709 the SDS-PAGE analysis.

710

711

Figure 2. Recombinant MUL_3720 and Hsp18 protein formulation linked with $\mathrm{R}_{4} \mathrm{Pam}_{2} \mathrm{Cys}$.

712 To analyse the formation of antigen-lipopeptide complexes, a constant amount of antigen (A)

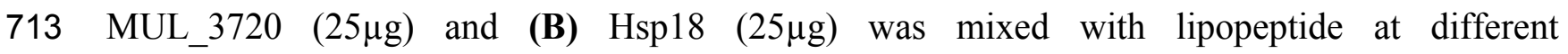
714 protein:lipopeptide molar ratios in $50 \mu \mathrm{l}$ of PBS. These graphs depict the absorbance values of 715 these solutions at an optical density of $450 \mathrm{~nm}\left(\mathrm{OD}_{450}\right)$. In these assays either $\mathrm{R}_{4} \mathrm{Pam}_{2} \mathrm{Cys}$ or $716 \mathrm{E}_{8} \mathrm{Pam}_{2} \mathrm{Cys}$ lipopeptides were added to the proteins at increasing amounts. The addition of

$717 \mathrm{R}_{4} \mathrm{Pam}_{2} \mathrm{Cys}$ is depicted with black circles and the addition of $\mathrm{E}_{8} \mathrm{Pam}_{2} \mathrm{Cys}$ is depicted with grey 718 squares. An increase in absorbance in correlation to an increase in lipopeptide was indicative of 719 protein binding to lipopeptide.

720

721 Figure 3. Antibody titres from BALB/c and C57BL/6 mice immunized with recombinant 722 MUL_3720 or Hsp18 linked to $\mathbf{R}_{\mathbf{4}} \mathbf{P a m}_{\mathbf{2}} \mathbf{C y s}$ lipopeptide adjuvant. MUL_3720-specific 723 antibody titres from (A) BALB/c and (B) C57BL/6 mice. Mice were vaccinated with protein alone 
724 (MUL_3720) (grey circles), recombinant protein $+\mathrm{R}_{4} \mathrm{Pam}_{2}$ Cys (blue circles), $\mathrm{R}_{4} \mathrm{Pam}_{2} \mathrm{Cys}$ alone 725 (clear circles) and M. bovis BCG (black circles). The error bars represent standard deviation (SD) $726(\mathrm{n}=7)$. A separate ELISA was performed to measure Hsp18-specific antibody titres in (C) BALB/c 727 and (D) C57BL/6 mice. Mice were vaccinated with protein alone (Hsp18) (grey circles), 728 recombinant protein $+\mathrm{R}_{4} \mathrm{Pam}_{2} \mathrm{Cys}$ (blue circles), $\mathrm{R}_{4} \mathrm{Pam}_{2}$ Cys alone (clear circles) and M. bovis 729 BCG (black circles). The error bars represent SD (n=7). Responses for day-63 post M. ulcerans 730 challenge highlighted by grey shading. $\operatorname{IgG}$ isotypes $\left(\operatorname{IgG}_{1}, \operatorname{IgG}_{2 \mathrm{a}}, \mathrm{IgG}_{2 \mathrm{~b}}\right.$ and $\left.\operatorname{IgG}_{3}\right)$ were quantified 731 from BALB/c mice immunized with (E) MUL_3720 + R ${ }_{4} \mathrm{Pam}_{2} \mathrm{Cys}$ and (F) Hsp18 $+\mathrm{R}_{4} \mathrm{Pam}_{2} \mathrm{Cys}$. 732 Mice were vaccinated with protein antigen alone (either MUL_3720 or Hsp18) (clear circles), 733 protein $+\mathrm{R}_{4} \mathrm{Pam}_{2} \mathrm{Cys}$ (grey circles) and $\mathrm{BCG}$ (black circles). Results are shown as zero if below 734 detectable limits. The error bars represent SD $(n=4)$. The null hypothesis (no difference in mean 735 antibody responses between treatment groups) was rejected at $* p<0.05,{ }^{* *} p<0.01,{ }^{* * *} p<0.001$ 736 or $* * * * p<0.0001$.

737

738 Figure 4. Progression of BU in the murine tail infection model over time. (A) Healthy mouse

739 tail. (B) Appearance of a small sign of redness at the site of tail infection. (C) Oedema surrounding 740 the initial site of redness. (D) Tail lesion at the point of ulceration. This is typically identified by 741 excessive oedema and redness at the site of imminent ulceration. Mice were culled before 742 ulcerative lesions appeared.

743

744 Figure 5. Vaccine performance using murine tail infection model of BU.

745 Survival analysis showing the time taken (days) for each mouse to reach ulceration for different

746 vaccination groups post M. ulcerans challenge. (A) Overview of the vaccination schedule. (B) 
747 Kaplan-Meier survival curves for: (B) BALB/c mice $(\mathrm{n}=7)$ and $(\mathbf{C})$ C57BL/6 mice (n=7). The null

748 hypothesis (no difference in mean antibody responses between treatment groups) was rejected if

$749 * p<0.05, * * p<0.01, * * * p<0.001$ or $* * * * p<0.0001$ 


\section{Figure 1}

SDS-PAGE and Western Blot Analysis of purified recombinant MUL_3720 and Hsp18 proteins.

(A) SDS-PAGE of MUL_3720 protein elution (containing $10 \mu \mathrm{g}$ protein) shows a band $\sim 36$

kDa. (B) SDS-PAGE of Hsp18 protein elution (containing $10 \mu \mathrm{g}$ protein) shows a band $\sim 18$

$\mathrm{kDa}$. (C) Protein in the final MUL_3720 elute was analysed by Western Blot using an anti-6xHIS-tag antibody to detect the presence of a single band corresponding to the band as the SDS- PAGE analysis. (D) Protein in the final Hsp18 elute was analysed by Western Blot using an anti-6xHIS-tag antibody to detect the presence of a single band corresponding to the $18 \mathrm{kDa}$ band as the SDS-PAGE analysis. 
A

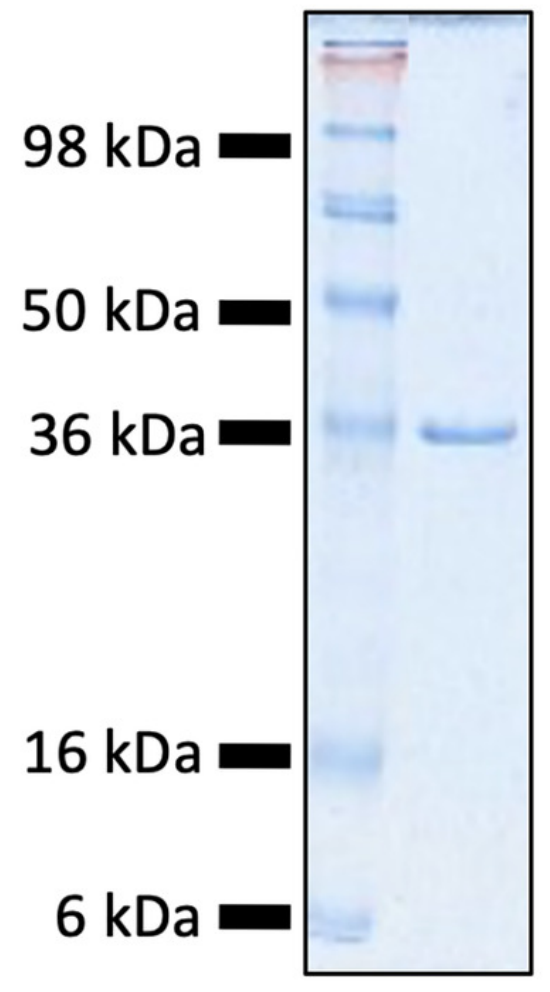

C

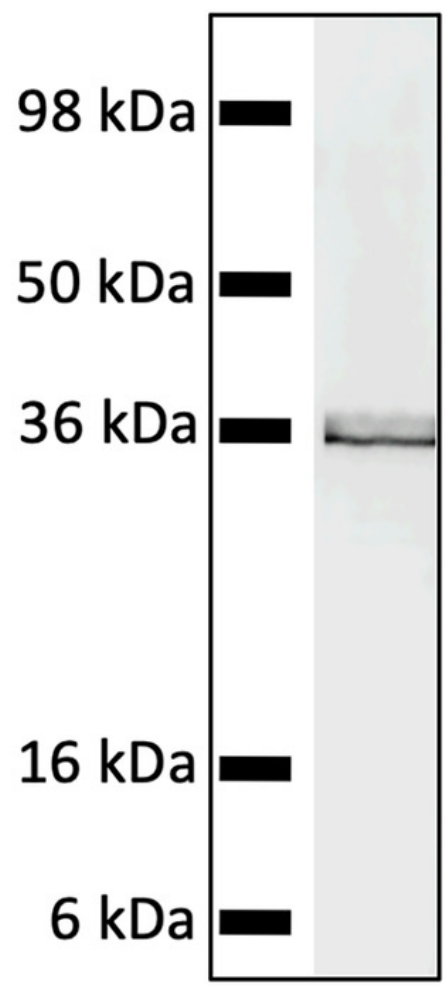

B

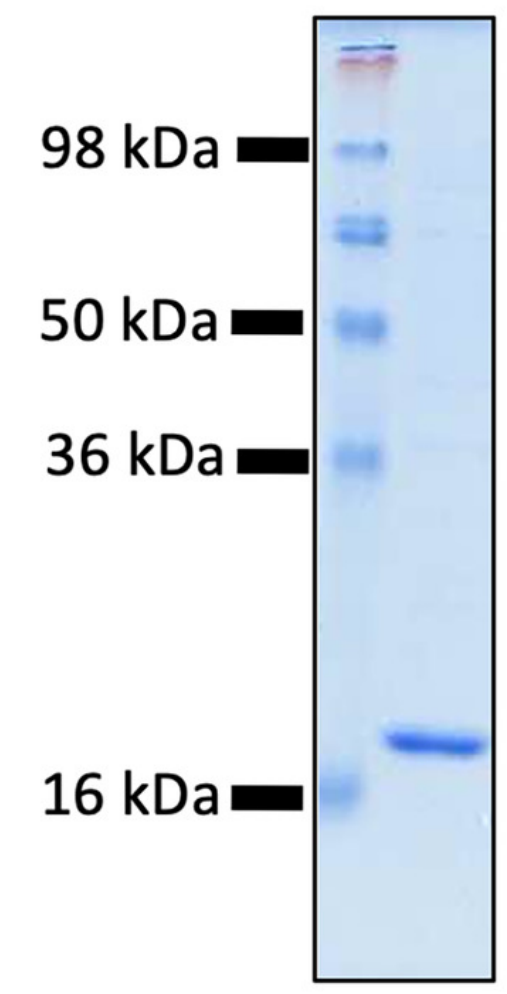

D

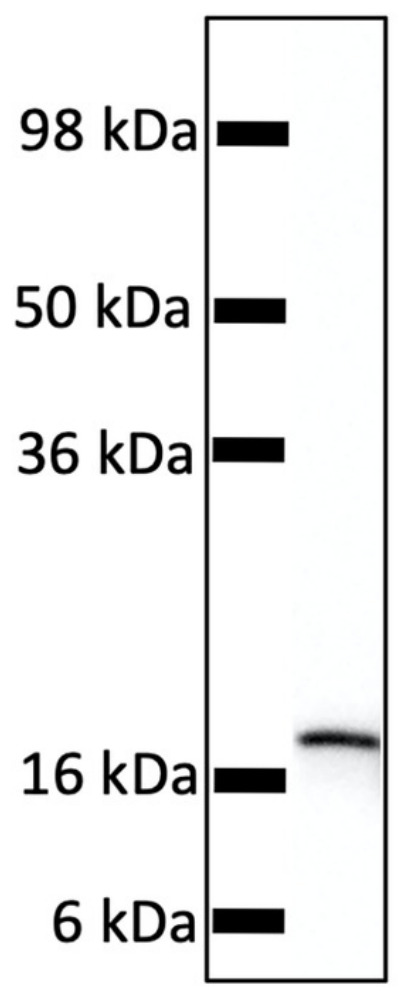




\section{Figure 2}

Recombinant MUL_3720 and Hsp18 protein formulation linked with $\mathrm{R}_{4} \mathrm{Pam}_{2} \mathrm{Cys}$.

To analyse the formation of antigen-lipopeptide complexes, a constant amount of antigen (A) MUL_3720 $(25 \mu \mathrm{g})$ and (B) Hsp18 $(25 \mu \mathrm{g})$ was mixed with lipopeptide at different protein:lipopeptide molar ratios in $50 \mu$ of PBS. These graphs depict the absorbance values of these solutions at an optical density of $450 \mathrm{~nm}\left(\mathrm{OD}_{450}\right)$. In these assays either $\mathrm{R}_{4} \mathrm{Pam}_{2} \mathrm{Cys}$ or $\mathrm{E}_{8} \mathrm{Pam}_{2} \mathrm{Cys}$ lipopeptides were added to the proteins at increasing amounts. The addition of $\mathrm{R}_{4} \mathrm{Pam}_{2} \mathrm{Cys}$ is depicted with black circles and the addition of $\mathrm{E}_{8} \mathrm{Pam}_{2} \mathrm{Cys}$ is depicted with grey squares. An increase in absorbance in correlation to an increase in lipopeptide was indicative of protein binding to lipopeptide. 
A

\section{MUL_3720 + lipopeptide}

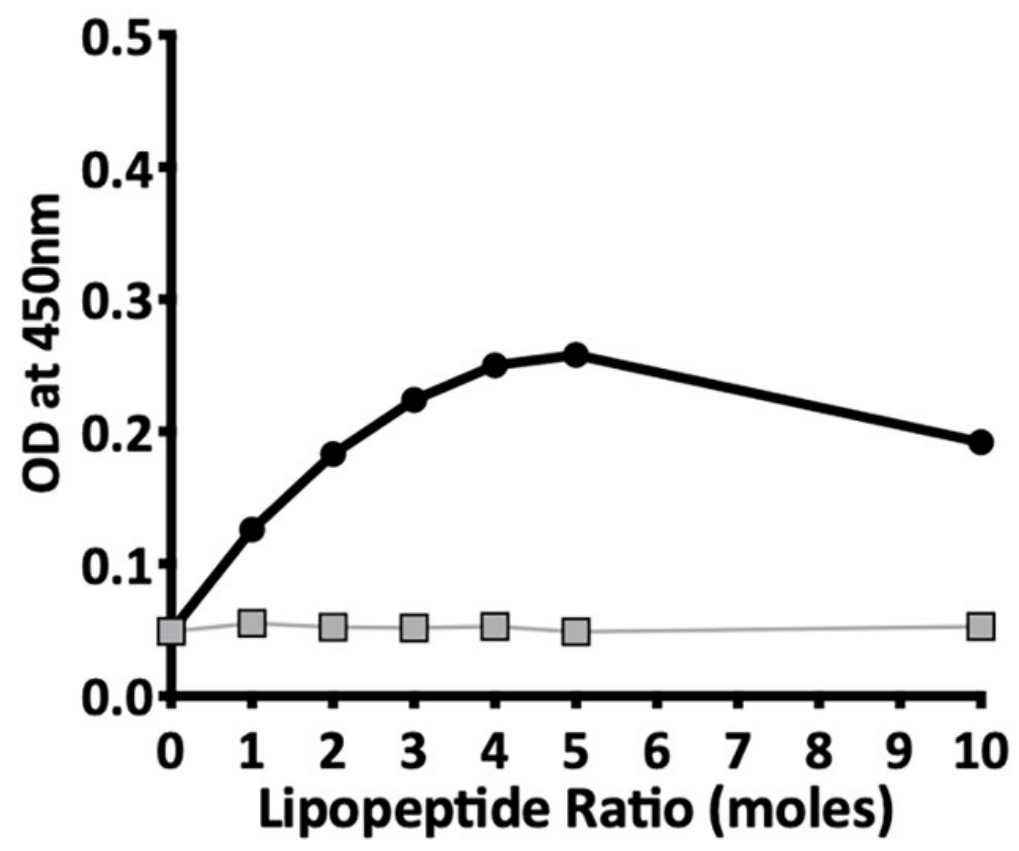

$\mathrm{R}_{\mathbf{4}}$ Pam $_{2}$ Cys

Postively charged moiety

$\square \mathrm{E}_{\mathbf{8}}$ Pam $_{\mathbf{2}}$ Cys

Negatively charged moiety

B

Hsp18 + lipopeptide

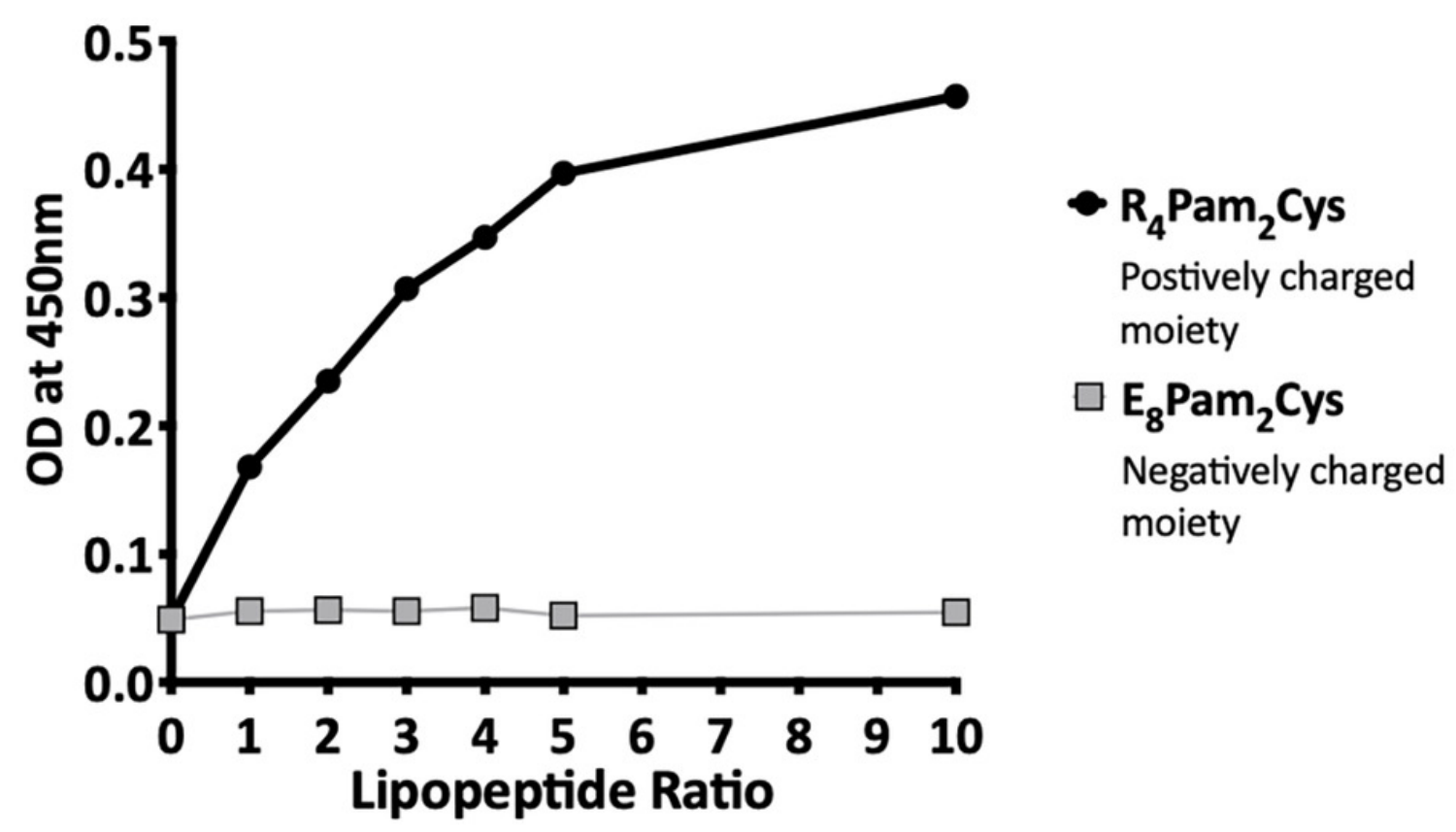




\section{Figure 3}

Antibody titres from BALB/C and C57BL/6 mice immunized with recombinant MUL_3720 or Hsp18 linked to $\mathrm{R}_{4} \mathrm{Pam}_{2} \mathrm{Cys}$ lipopeptide adjuvant.

MUL_3720-specific antibody titres from (A) BALB/C and (B) C57BL/6 mice. Mice were vaccinated with protein alone (MUL_3720) (grey circles), recombinant protein $+\mathrm{R}_{4} \mathrm{Pam}_{2} \mathrm{Cys}$ (blue circles), $\mathrm{R}_{4} \mathrm{Pam}_{2} \mathrm{Cys}$ alone (clear circles) and $\mathrm{M}$. bovis BCG (black circles). The error bars represent standard deviation (SD) $(n=7)$. A separate ELISA was performed to measure Hsp18-specific antibody titres in (C) BALB/C and (D) C57BL/6 mice. Mice were vaccinated with protein alone (Hsp18) (grey circles), recombinant protein $+\mathrm{R}_{4} \mathrm{Pam}_{2} \mathrm{Cys}$ (blue circles), $\mathrm{R}_{4} \mathrm{Pam}_{2} \mathrm{Cys}$ alone (clear circles) and M. bovis BCG (black circles). The error bars represent SD $(n=7)$. $\lg G$ isotypes ( $\lg _{1}, \lg G_{2 a}, \lg G_{2 b}$ and $\left.\lg G_{3}\right)$ were quantified from $B A L B / c$ mice immunized with (E) MUL_3720 + $\mathrm{R}_{4} \mathrm{Pam}_{2} \mathrm{Cys}$ and (F) Hsp18 $+\mathrm{R}_{4} \mathrm{Pam}_{2}$ Cys. Mice were vaccinated with protein antigen alone (either MUL_3720 or Hsp18) (clear circles), protein $+\mathrm{R}_{4} \mathrm{Pam}_{2} \mathrm{Cys}$ (grey circles) and BCG (black circles). Results are shown as zero if below detectable limits. The error bars represent $S D(n=4)$. The null hypothesis (no difference in mean antibody responses between treatment groups) was rejected at ${ }^{*} p<0.05$, ${ }^{* *} p<0.01$, ${ }^{* * *} p<0.001$ or $* * * * p<0.0001$. 
A

\section{BALB/c}

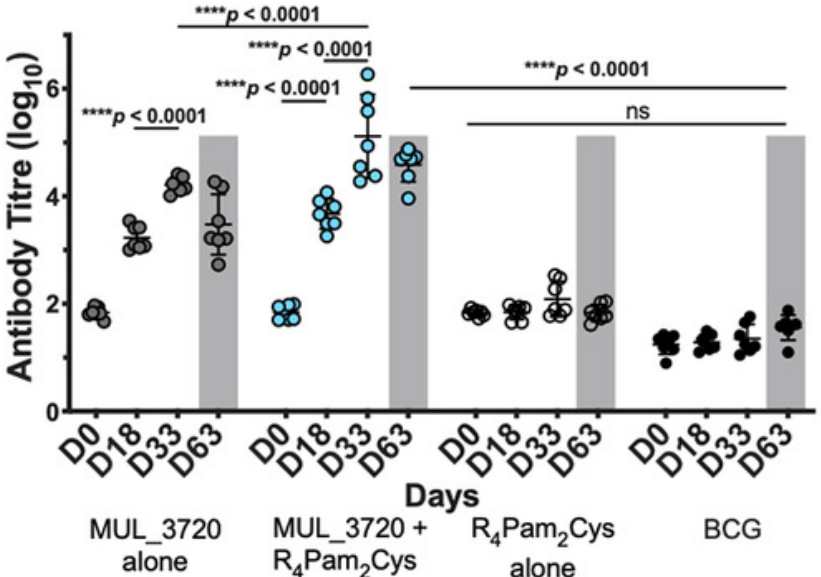

C

BALB/c

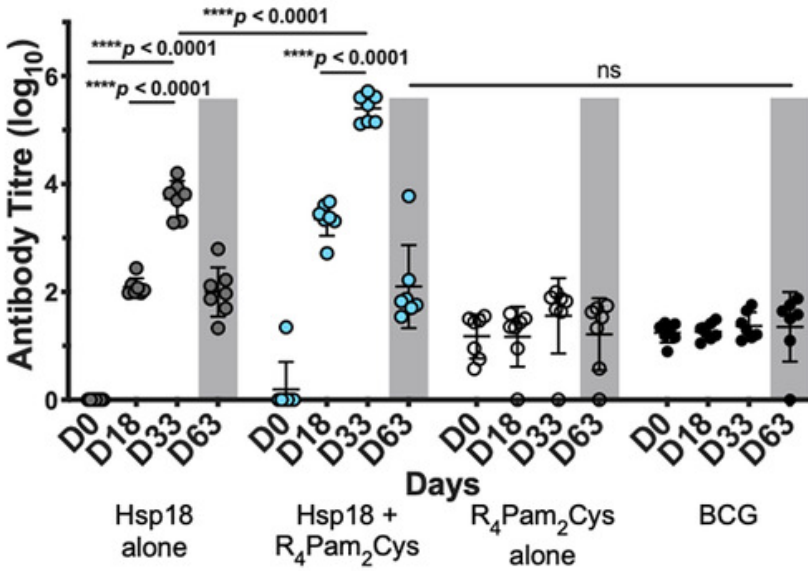

E

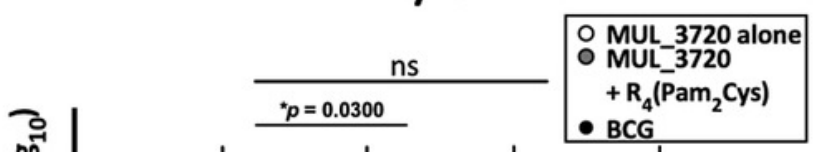

B

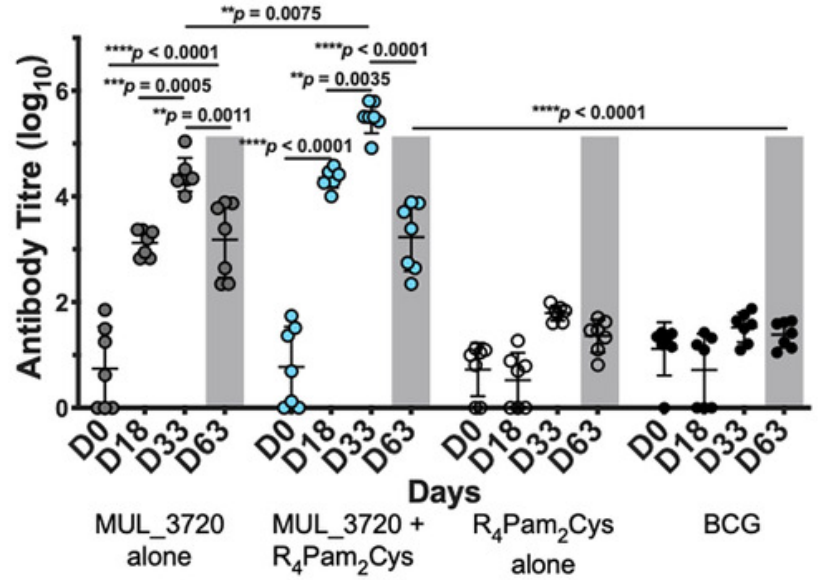

D

C57BL/6

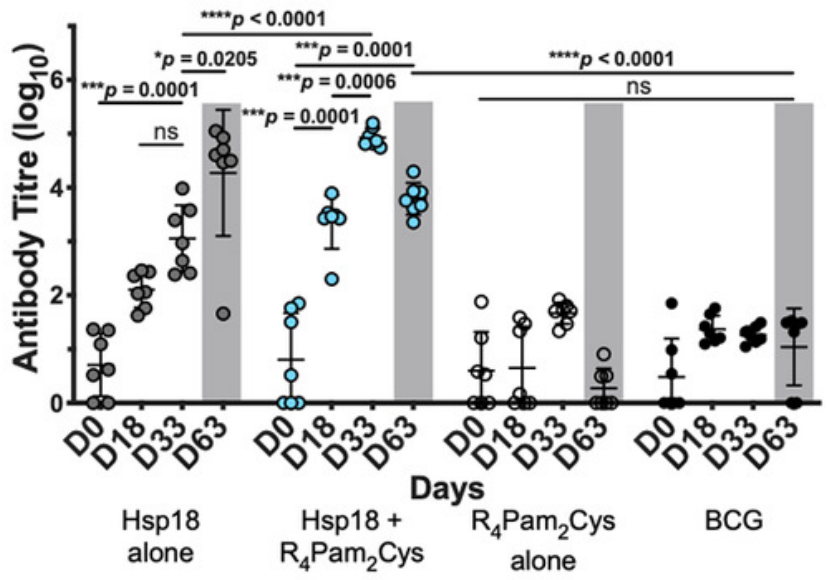

F

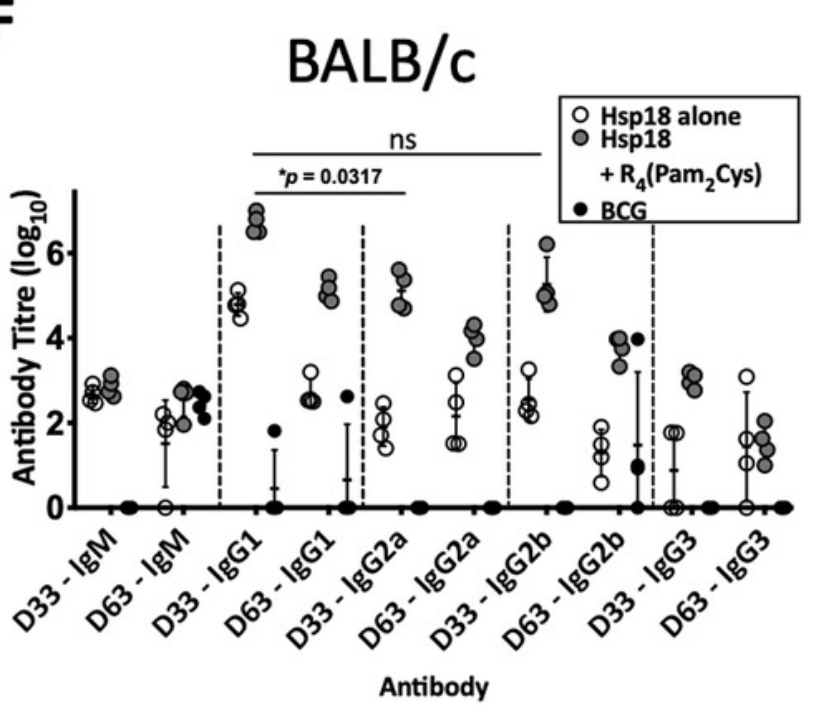




\section{Figure 4}

Progression of $\mathrm{BU}$ in the murine tail infection model over time.

(A) Healthy mouse tail. (B) Appearance of a small sign of redness at the site of tail infection.

(C) Oedema surrounding the initial site of redness. (D) Tail lesion at the point of ulceration.

This is typically identified by excessive oedema and redness at the site of imminent ulceration. Mice were culled before ulcerative lesions appeared.

\section{Stages of M. ulcerans tail infection}

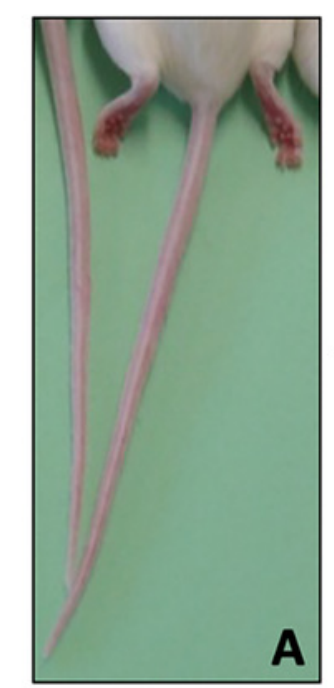

no symptoms redness

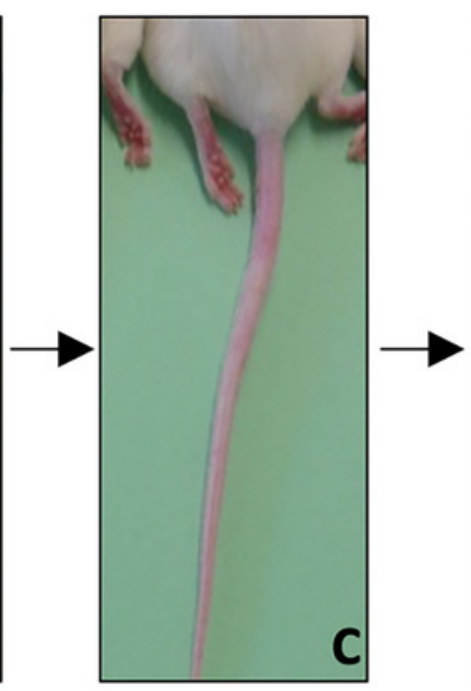

oedema

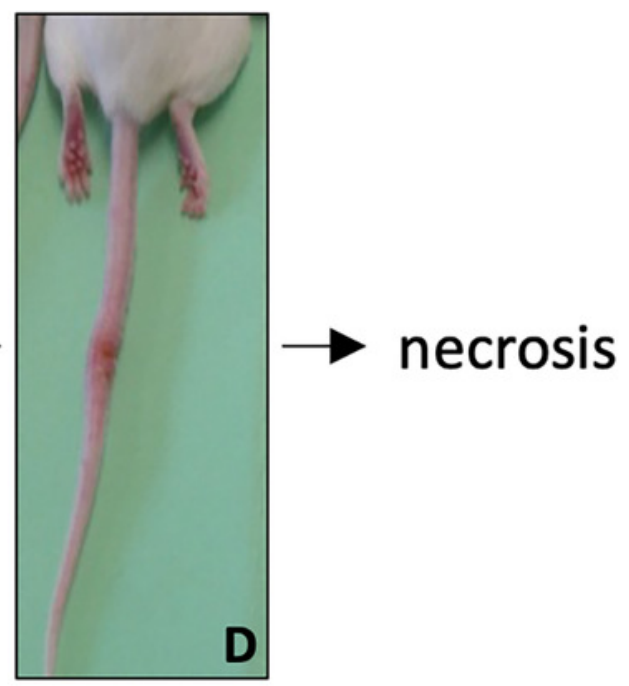

ulceration

experimental

endpoint 


\section{Figure 5}

Vaccine performance using murine tail infection model of BU.

Survival analysis showing the time taken (days) for each mouse to reach ulceration for different vaccination groups post M. ulcerans challenge. (A) BALB/C mice $(n=7)$ and (B) C57BL/6 mice $(n=7)$. The null hypothesis (no difference in mean antibody responses between treatment groups) was rejected if ${ }^{*} p<0.05,{ }^{* *} p<0.01,{ }^{* * *} p<0.001$ or ${ }^{* * *} p<0.0001$. 
A

Vaccinate

Hsp18 or MUL_3720

$+\mathrm{R}_{4} \mathrm{Pam}_{2} \mathrm{Cys}$

$\downarrow$

DO

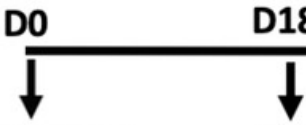

Harvest

sera

\section{Vaccination and Challenge Model}

Boost

Hsp18 or MUL_3720

+ R4Pam2Cys

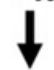

D21

D33

Challenge

M. ulcerans

(1x10 $\mathrm{CFU})$

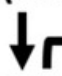

Monitor mice

for ulceration

D35

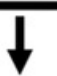

Harvest

sera

D63

sera
Experiment endpoint

B

$\mathrm{BALB} / \mathrm{c}$

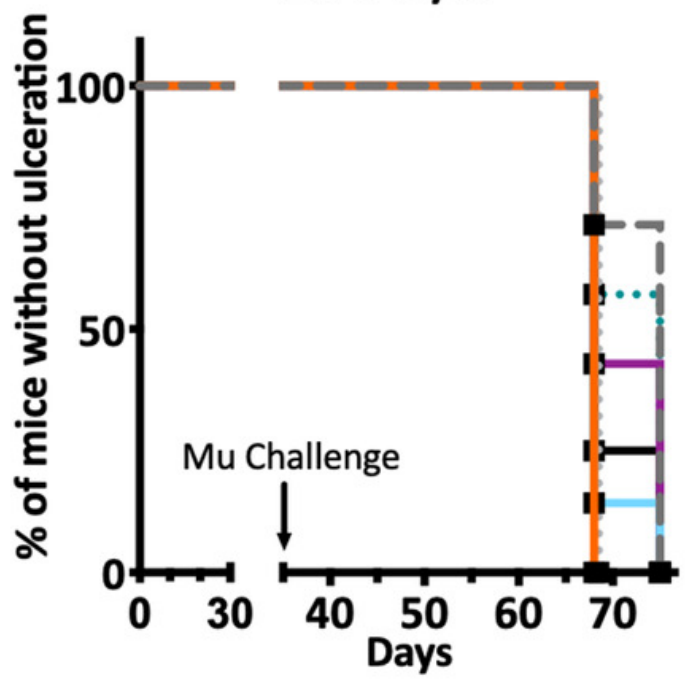

Hsp18 alone

$\mathrm{R}_{4}$ Pam $_{2}$ Cys without Hsp18

MUL_3720 alone

$\mathrm{R}_{4} \mathrm{Pam}_{2}$ Cys without MUL_3720

$-\mathrm{Hsp} 18+\mathrm{R}_{4} \mathrm{Pam}_{2}$ Cys

-. MUL_3720 + R Pam $_{2}$ Cys

BCG

D75

Harvest

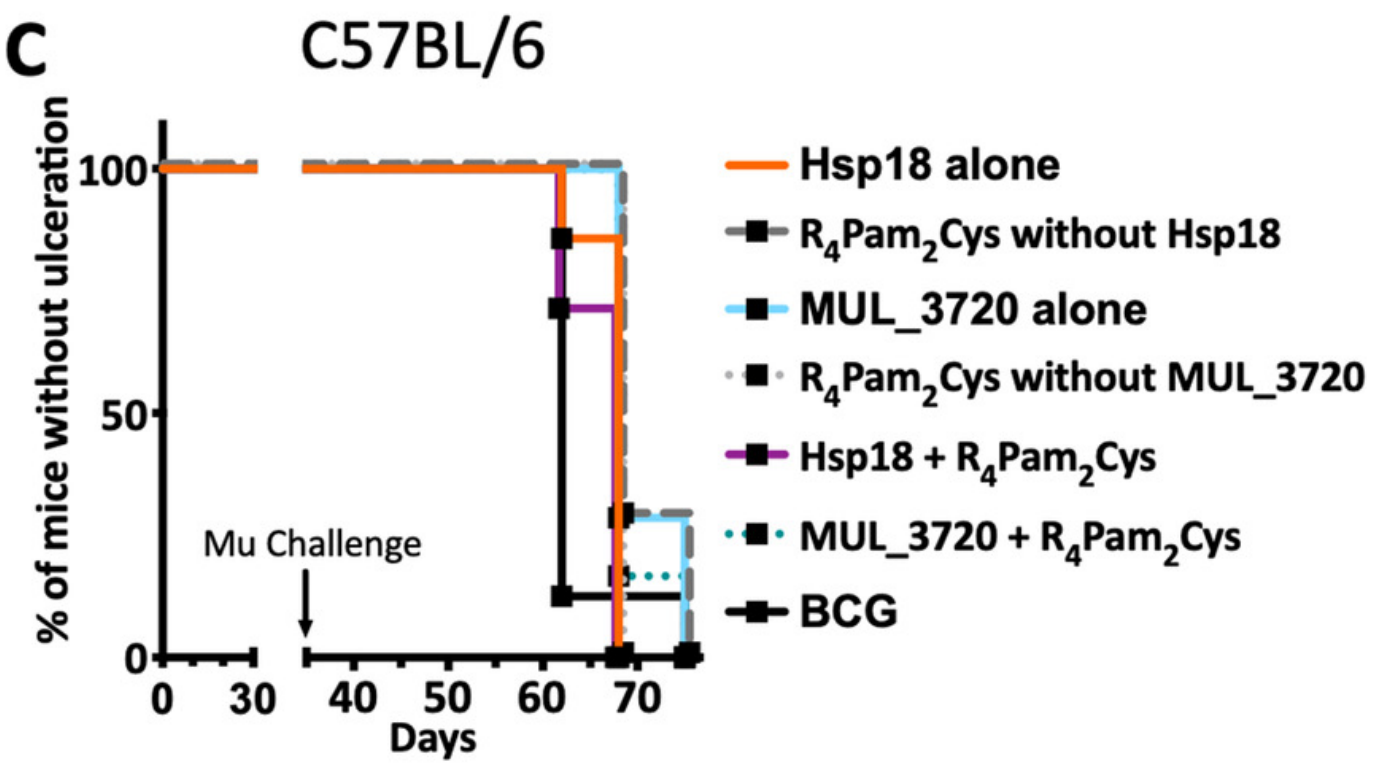

